\title{
Experimental Study on Cross-ventilation of a Generic Building in Highly-dense Urban Areas: Impact of Planar Area Density and Wind Direction
}

\author{
Mohammadreza Shirzadia ${ }^{\text {, Yoshihide Tominaga }}{ }^{a}$, Parham A. Mirzaei ${ }^{\text {b1 }}$ \\ a Wind and Fluid Engineering Research Center, Niigata Institute of Technology, \\ Kashiwazaki, Japan
}

${ }^{b}$ Architecture and Built Environment Department, University of Nottingham, Nottingham, UK

\begin{abstract}
This study presents the experimental results on cross-ventilation in a generic low-rise building placed in highly-dense urban configurations. Flow visualization studies were conducted by utilization of a smoke generator in order to investigate the nature of the flow pattern inside and around the cross-ventilated building. Moreover, distribution of the wind surface pressure coefficients over windward and leeward façades and internal walls of the target building were measured using a pressure tap system. Furthermore, the airflow rate crossing through the openings was measured using a tracer gas method. Different building configurations, representing highly-dense urban areas, as well as different wind angles were investigated in this study
\end{abstract}

Surprisingly, the experimental results reveal a noticeable difference between the mechanism of cross-ventilation in moderately-dense and highly-dense buildings arrangements. A clear leeward jet with a highly-transient nature can be observed, which is generated due to a leeward vortex formed by the target and downstream buildings. As another novel finding of this study, the crossventilation is understood to be highly transient in highly-dense urban areas with a strong periodic fresh air pulsation through the windward and leeward openings. This behavior is fundamentally far from the steady state models considered for such cross-ventilation scenarios in literature.

Keywords: Wind tunnel experiment, cross-ventilation, urban areas, wind surface pressure, tracer gas, CFD

\footnotetext{
${ }^{1}$ Corresponding author at: University Park, Nottingham, NG2RD, UK.

Parham.Mirzaei_Ahranjani@nottingham.ac.uk
} 


\section{Introduction}

Rapid growth of urbanization and population in recent years has resulted in emerging large numbers of mega cities with highly-dense urban areas (OECD, 2012). Tokyo and Hong Kong are two examples of mega cities with highly-dense urban configurations, struggling from poor outdoor air quality and thermal comfort due to weak urban ventilation caused by closely packed building arrangement (Ishida et al., 2018; Yang and Li, 2011). Weak urban ventilation has a significant effect on building energy consumption, pedestrian health, and indoor air quality (Luo et al., 2011; Mirzaei and Haghighat, 2011; Yang et al., 2019). These important parameters have encouraged many researches in urban studies to scrutinize the physics of the wind distribution in highly-dense urban areas and its relations to urban ventilation (Ramponi et al., 2015; Wu et al., 2015), building energy (Aboelata and Sodoudi, 2019; Lu and Du, 2019; Mirzaei et al., 2015; Shirzadi et al., 2018b), pedestrian health and comfort (Tan et al., 2019; Wang et al., 2017), and pollution dispersion (Gryning and Batchvarova, 2009; Yuan et al., 2014).

Cross-ventilation, as a most common form of natural ventilation, is known to be directly linked to the urban ventilation, wind distribution around buildings, and building arrangements (Aflaki et al., 2015; Gautam et al., 2019; Kotani et al., 2009). Cross-ventilation can be an effective method for improving the building energy saving (Abdullah and Wang, 2012; Guo et al., 2015; Li et al., 2016; Mochida et al., 2006, 2005) and indoor thermal comfort (Hesaraki et al., 2015; Mochida et al., 2005; Prakash and Ravikumar, 2015). It is also an important element in sustainable design of modern and traditional buildings (Aydin and Mirzaei, 2016). Nonetheless, physics behind crossventilation and its performance in highly-dense building arrangements are not yet well understood although complexity of airflow field in dense building arrangements has been widely studied both experimentally (Becker et al., 2002; Cheng and Castro, 2002; Mfula et al., 2005) and numerically (Wang et al., 2017; Yuan et al., 2014).

In highly-dense urban areas, the turbulent diffusion plays an important role in the vertical momentum transport and urban ventilation resulted by non-uniformity of buildings heights (Ishida et al., 2018). Furthermore, the unsteady effects become more important across dense building areas where the turbulent fluctuations dominates over the mean flow (Coceal et al., 2006). In wind tunnel experimental studies by (Shirzadi et al., 2019; Tominaga and Blocken, 2015) and (Ikegaya et al., 2019), the importance of transient nature of flow field in a cross-ventilated building placed in dense building configuration is clearly addressed.

Furthermore, performance of cross-ventilation in urban areas has been studied using different methods, including field measurement (H. Gough et al., 2018; H. L. Gough et al., 2018; Lo and Novoselac, 2012; Mochida et al., 2006, 2005; Park, 2013), wind tunnel measurement (Ikegaya et al., 2019; Shirzadi et al., 2019; Tominaga and Blocken, 2015), and utilization of computational fluid dynamics (CFD) models (King et al., 2017b, 2017a; Shirzadi et al., 2018a, 2018b; Tong et al., 2016). The importance of considering the surrounding buildings and obstacles on the crossventilation performance was emphasized in these studies. For example, significant reduction of cross-ventilation parameters (e.g., crossing airflow rate and mean age of air) was reported for several sheltered building case studies. In the case of highly-dense building configurations, there is a lack of cross-ventilation studies. In most of these studies, where a cluster of buildings in 
generic forms were considered (H. L. Gough et al., 2018; Ikegaya et al., 2019; King et al., 2017b, 2017a; Shirzadi et al., 2018a, 2018b; Tong et al., 2016), a constant planar area ratio of 0.25, which is a representation of moderate-dense building arrangement, was mainly investigated.

In the numerical studies such as the one by (Shuhaimi et al., 2017), the cross-ventilation of a group of generic building forms with higher planar area ratio of $0.25,0.35$, and 0.5 are simulated using steady Reynolds-averaged Navier Stoke (SRANS) models. Nevertheless, these simulation studies have only been validated using wind tunnel experimental data for an unsheltered building case studies (Ohba et al., 2001). Not only the planar area ratio, but also the approaching wind angle are the key factor in the cross-ventilation of sheltered building case (King et al., 2017b; Shirzadi et al., 2018b) as they change the distance between buildings and also the projected area toward wind.

Due to the importance and complexity of cross-ventilation in urban areas and evident lack of knowledge in literature, a framework is stablished to investigate the physics of cross-ventilation in highly-dense urban areas by conducting a series of wind tunnel measurements and numerical studies. Recently, the authors reported the results of a wind tunnel experimental measurements for cross-ventilation in a sheltered building with a fixed planar area ratio (Shirzadi et al., 2019). In contrast to the previous paper, this paper reports on an experimental wind tunnel study of crossventilation in a group of generic low-rise buildings with different planar area ratios against different wind angles. First, the surface wind pressure over the building surfaces and crossing airflow rate through the building openings are measured. Furthermore, a series of flow visualization studies are conducted in order to investigate the transient nature of cross-ventilation and airflow distribution not only inside the building, but also around the buildings. Details of the measurement techniques are presented in Section 2. In Section 3, results of flow visualization are presented while in Sections 4 and 5, results of the surface wind pressure and crossing airflow rate measurements are discussed. Finally, the concluding remarks of the study are presented in Section 6.

\section{Description of the experimental measurements}

\subsection{Wind tunnel specification}

Experimental measurements were conducted in the atmospheric boundary layer wind tunnel at Niigata Institute of Technology, Japan (Akabayashi et al., 1996; Kubota et al., 2008; Tominaga and Stathopoulos, 2011; Yoshie et al., 2007). The wind tunnel has the test section with dimensions of $1.8 \mathrm{~m} \times 1.8 \mathrm{~m}$ and the length of $13 \mathrm{~m}$. Roughness elements were used to create a neutral boundary layer in the wind tunnel test section. A schematic of the wind tunnel and the vertical profiles of the time-averaged streamwise velocity $\left(\frac{U(z)}{U_{H}}\right)$ and turbulent kinetic energy $\left(\frac{k(z)}{U_{H}^{2}}\right)$ measured at the center of the empty turntable are shown in Figure 1. The time-averaged streamwise velocity at the reference height $(H=0.16 \mathrm{~m})$, aerodynamic roughness, and friction

velocity of the wind tunnel were respectively $U_{H}=5.233 \frac{\mathrm{m}}{\mathrm{s}}, z_{0}=0.00033 \mathrm{~m}$, and $u^{*}=0.33 \frac{\mathrm{m}}{\mathrm{s}}$ (Tominaga et al., 2008). Moreover, the created fully rough boundary layer had a roughness Reynolds number of 8.0 (Snyder and Castro, 2002; Uehara et al., 2003). 


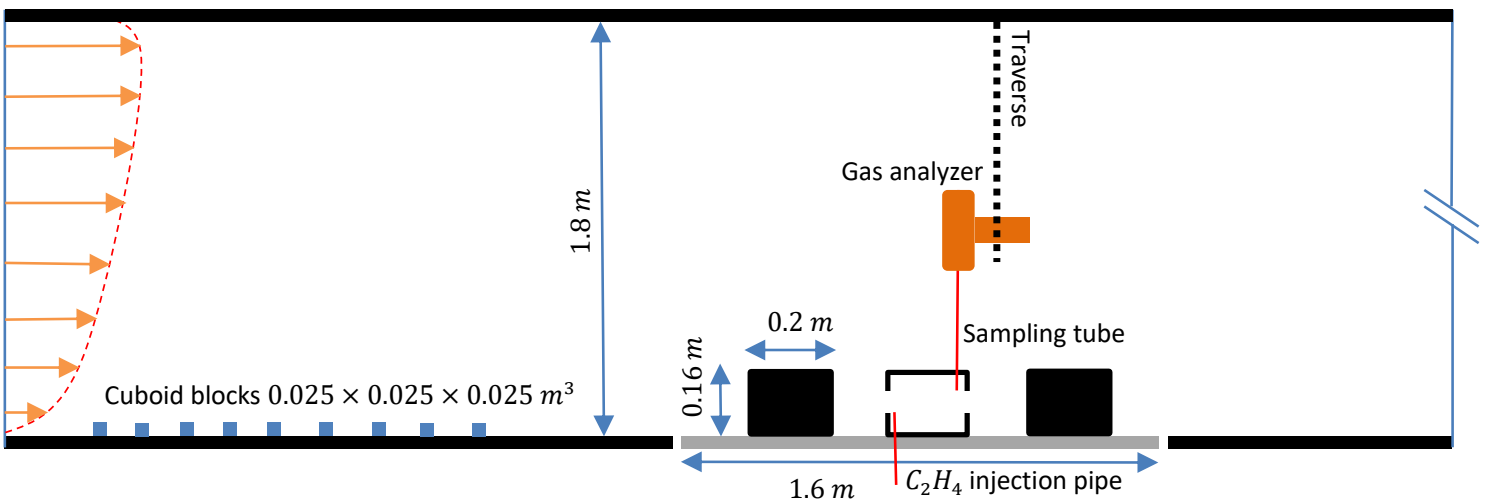

(a)

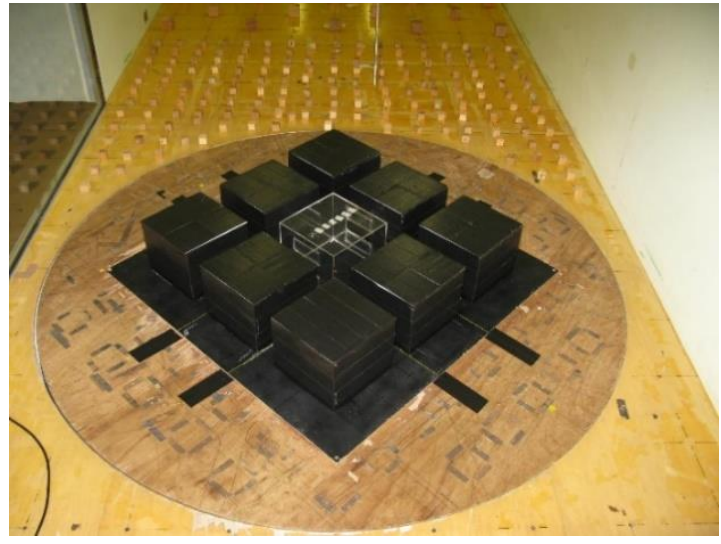

(b)

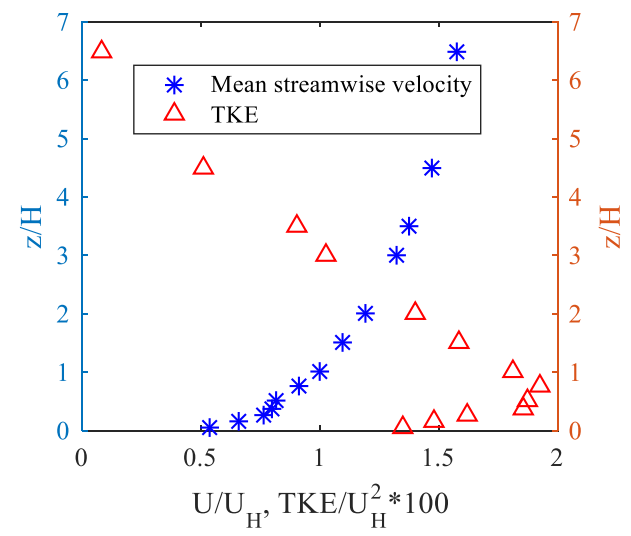

(c)

Figure 1 (a) A schematic of the wind tunnel, (b) wind tunnel test configuration for a planar area ration of $\lambda_{P}=$ 0.6 , (c) vertical profile of the time-averaged streamwise velocity and turbulent kinetic energy (TKE) at the center of the empty turntable

\subsection{Buildings dimensions and arrangements}

As shown in Figure 2, nine cuboid buildings with dimensions of $B \times D \times H=0.2 \mathrm{~m} \times 0.2 \mathrm{~m} \times$ $0.16 \mathrm{~m}$ were placed on the center of the turntable in a regular arrangement at three different planar area ratios of $\lambda_{P}=0.25, \lambda_{P}=0.4$, and $\lambda_{P}=0.6$, which represent different urban areas of moderately- and highly-dense. The planar area ratio is defined as (Quan et al., 2007):

$$
\lambda_{P}=\frac{B D}{(B+w)(D+W)}
$$

where $B$ and $D$ are the building's breadth and depth, respectively. $W$ is the distance between buildings set as $0.200 \mathrm{~m}, 0.116 \mathrm{~m}$, and $0.058 \mathrm{~m}$ at the planar area ratios of $0.25,0.4$, and 0.6 , respectively. The target building has two openings at the windward and leeward façades with dimensions of $0.036 \mathrm{~m} \times 0.092 \mathrm{~m}$. All surrounding buildings have no openings in order to minimize the complexity of the flow pattern. 


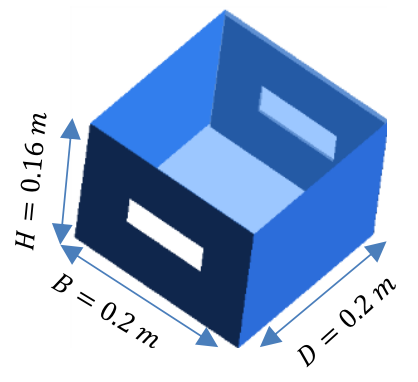

(a)

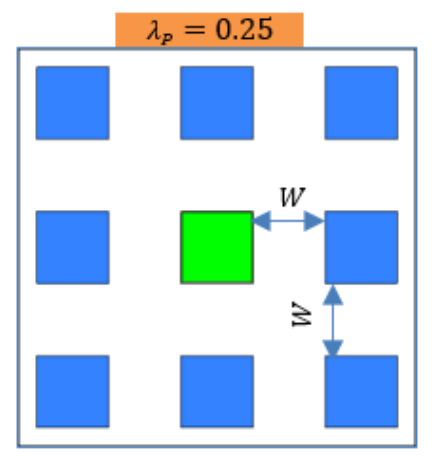

Figure 2 (a) Building and opening dimensions, (b) wh

\subsection{Measurements details}

\subsubsection{Flow visualization}

In order to have an insight into the flow distribution around and inside the buildings, a series of flow visualizations were conducted by using a laser light sheet, a digital video camera, and a smoke generator. Pictures were taken at a frequency of $30 \mathrm{~Hz}$ over the vertical central plane and horizontal plane at the height of $\frac{Z}{H}=0.5$ (see Figure 3). For the inside flow field visualization, the method presented in (Tominaga and Blocken, 2015) was used while for the outdoor flow field visualization the smoke was released from a location upstream of the buildings. Four of the surrounding buildings models were made from acrylic glass, a transparent material, and were placed across the intercepting planes at different wind angles and building arrangements.

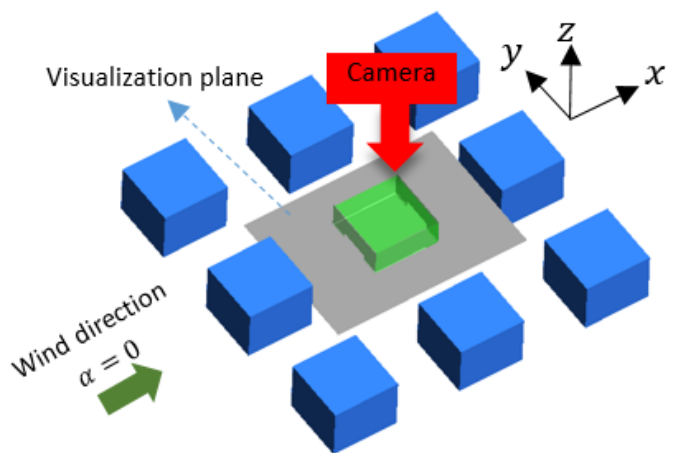

(a)

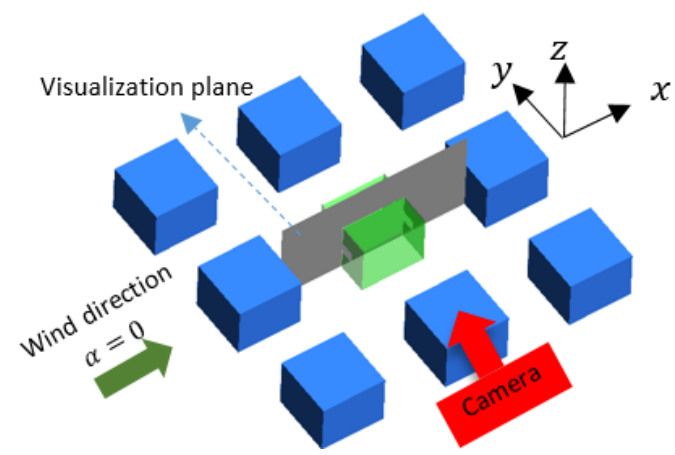

(b)

Figure 3 Position of the camera for flow visualization over (a) horizontal and (b) vertical planes 


\subsubsection{Surface wind pressure measurement}

Surface wind pressure measurement was conducted using a multi-point transducer (Kyowa Electronic Instruments; F94-2206) (Tominaga et al., 2015). As shown in Figure 4, the wind surface pressures over the target building's internal and external surfaces were measured using a pressure tapping system. The external surface pressures were measured by eight pressure taps installed around the external surfaces of windward and leeward openings at a distance of $d=$ $0.015 \mathrm{~m}$ from the openings' edges. The internal surface pressures over the internal walls of the building were measured by three pressure taps installed at the center of the ceiling and sidewalls. The blockage ratio of the pressure tubes inside the building was minimized by fixing all the pressure tubes to the building walls in a way that they made no flow disruption inside the building.

The surface-averaged pressure coefficient for the windward $\left(C_{P}^{w w}\right)$, leeward $\left(C_{P}^{l w}\right)$, and internal surfaces $\left(C_{P}^{\text {int }}\right)$ are calculated as bellow:

$$
\begin{aligned}
& \overline{C_{P}^{w w}}=\frac{1}{4} \sum_{i=1}^{4} \frac{P-P_{r e f}}{\frac{1}{2} \rho U_{H}^{2}} \\
& \overline{C_{P}^{l w}}=\frac{1}{4} \sum_{i=1}^{4} \frac{P-P_{r e f}}{\frac{1}{2} \rho U_{H}^{2}} \\
& \overline{C_{P}^{l n t}}=\frac{1}{4} \sum_{i=1}^{3} \frac{P-P_{r e f}}{\frac{1}{2} \rho U_{H}^{2}}
\end{aligned}
$$

where $P_{r e f}$ and $\rho$ are the reference pressure and air density, respectively. The reference pressure sensor was installed at a distance of about $1 \mathrm{~m}$ upstream the turntable at a height of $0.6 \mathrm{~m}$. Definition of location of the reference pressure in CFD models is quite challenging (Montazeri and Blocken, 2013). Hence, the pressure difference across the windward and leeward façades $\left(\Delta C_{P}^{w w}, \Delta C_{P}^{l w}\right)$ and the total pressure difference across the building $\left(\Delta C_{P}^{t o t a l}\right)$ are defined to make a practical comparison between CFD and experimental results. These values are independent from the reference pressure definition and are defined as follows:

$$
\begin{aligned}
& \Delta C_{P}^{\text {total }}=\overline{C_{P}^{w w}}-\overline{C_{P}^{l w}} \\
& \Delta C_{P}^{w w}=\overline{C_{P}^{w w}}-\overline{C_{P}^{l n t}} \\
& \Delta C_{P}^{l w}=\overline{C_{P}^{l n t}}-\overline{C_{P}^{l w}}
\end{aligned}
$$

A sampling rate of $100 \mathrm{~Hz}$ and a sampling time of 60 seconds were considered for pressure measurement. All measurements were repeated five times due to the very large fluctuation of the surface wind pressure. Pressure measurement was conducted for both unsheltered and sheltered building conditions with the planar area ratios of 0.0 (unsheltered building scenario), $0.25,0.4$, and 0.6 against the wind angles between $0^{\circ}$ and $90^{\circ}$ with a $15^{\circ}$ increment. The uncertainty of the surface pressure measurement was estimated to be about $5 \%$ (Shirzadi et al., 2019). 

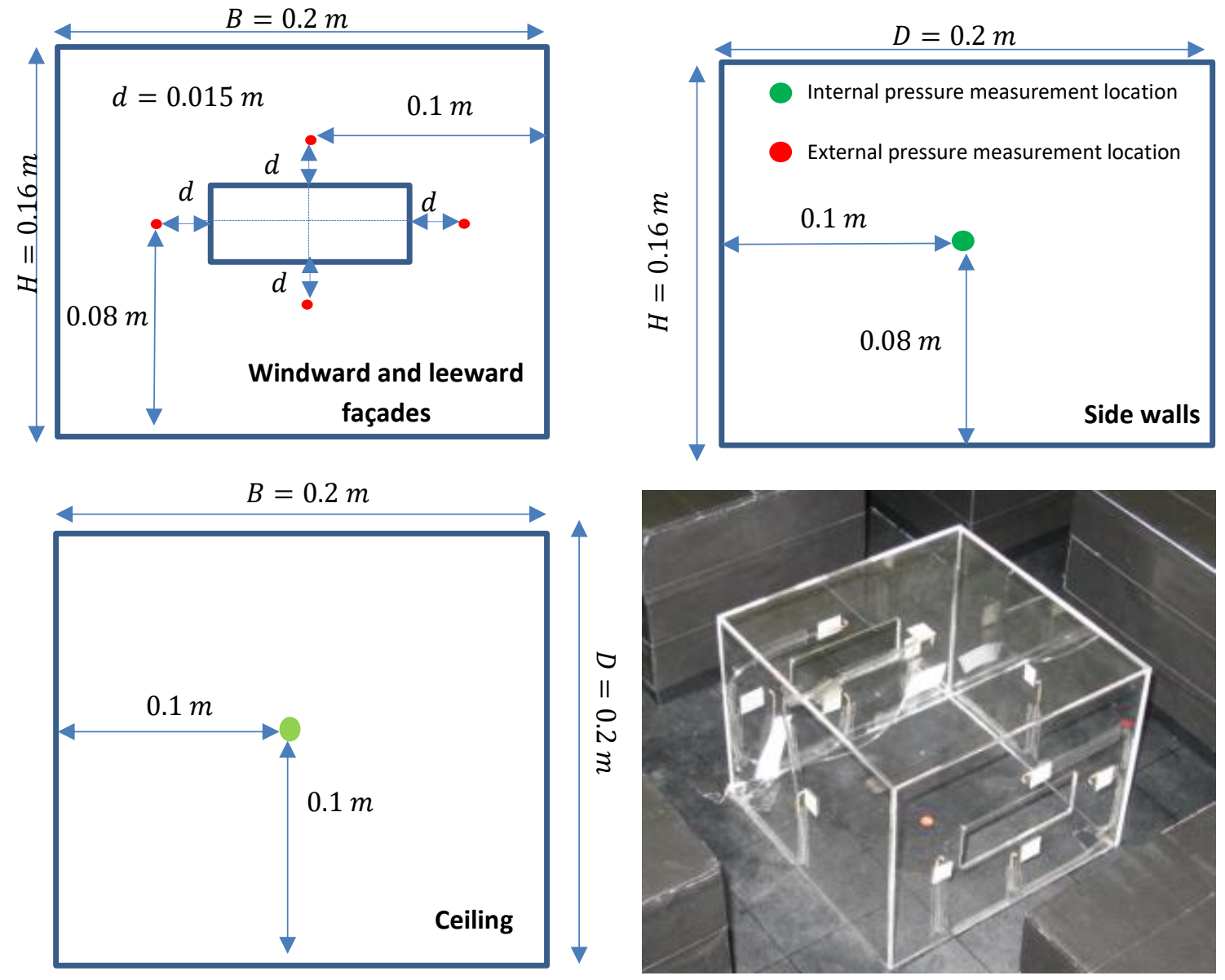

Figure 4 Location of the pressure taps over the building surfaces

\subsubsection{Airflow rate measurement}

Airflow rate measurement was employed with a tracer gas method. As shown in Figure 5, a constant flow rate of Ethylene gas with 2,000 ppm concentration was injected near the windward opening while the mean concentration was measured near the leeward opening by using a highspeed total hydrocarbon analyzer (Technica, HTHCA-01). Diameter of the sampling tube is less than $2 \mathrm{~mm}$, which is quite small in comparison to the building dimension; hence, it has a minor effect on the flow field inside the building. The crossing airflow rate through the opening is calculated using the following relation:

$$
q_{\text {opening }}=\frac{q_{\text {inlet }}}{\overline{C_{\text {outlet }}}}
$$

where $q_{\text {inlet }}$ and $\bar{C}_{\text {outlet }}$ are the tracer gas injection flow rate and mean concentration near the leeward opening, respectively. Concentration measurement was performed over a sampling time of $60 s$ while all measurements were repeated several times by changing the location of the 
injection point and sampling tube to ensure a fully-mixed condition for the injected gas inside the building. The concentration resolution and time response of the hydrocarbon analyzer were $10 \mathrm{ppm}$ and $25 \mathrm{~ms}$, respectively (Shirzadi et al., 2019; Tominaga and Blocken, 2015). The airflow measurement was done for the unsheltered and sheltered buildings and for the planar area ratios of $0.0,0.25,0.4$, and 0.6 against the wind angles between $0^{\circ}$ and $90^{\circ}$ with a $15^{\circ}$ increment. The uncertainty of the measurement was about $7 \%$ (Shirzadi et al., 2019).

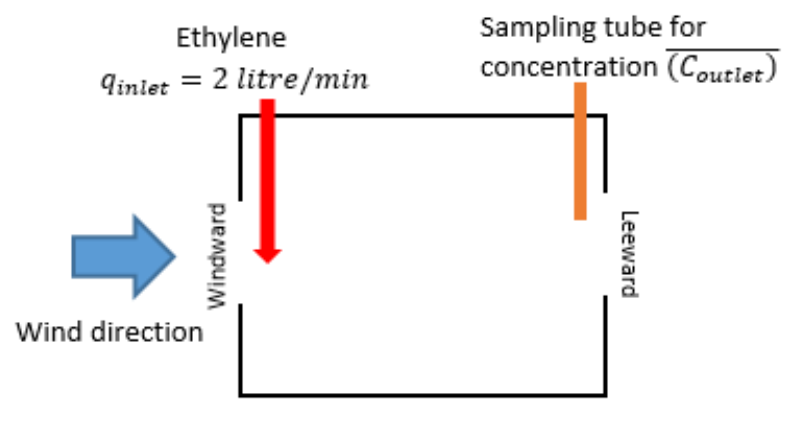

(a)

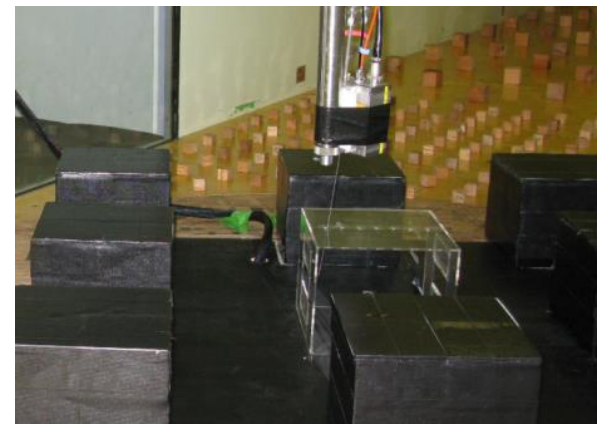

(b)

Figure 5 (a) A schematic of the airflow rate measurement, and (b) sampling tube inside the building

\section{Flow visualization results}

In order to compare the flow distribution characteristics at highly-dense urban configurations, i.e. of $\lambda_{P}=0.4$ and $\lambda_{P}=0.6$, with those at moderately-dense configuration, i.e., of $\lambda_{P}=0.25$, the instantaneous flow field over the vertical central plane inside the target building at $\lambda_{P}=0.25$ is shown in Figure 6 against the wind angle of $\alpha=0^{\circ}$. For flow visualization a time interval of $\Delta t=$ $0.2 s$ is selected to observe the velocity fluctuations inside and around the buildings. The incoming fresh air through the windward opening shows a transient behavior where a flapping jet is formed. As shown by (Tominaga and Blocken, 2015), the direction of the mean velocity of the incoming jet is highly oriented toward the ground. Inversely, the instantaneous pattern of the jet indicates that the jet oscillates in a wider range (see Figure 6(a) and Figure 6(i)). The Kelvin-Helmholtz instability can be observed during the flow visualization over the horizontal central plane (not shown here). Furthermore, the flapping behavior of the incoming jet is presented in the horizontal plane while the vortices released from the incoming jet impinge on the building's side walls periodically during the jet oscillation in the horizontal plane. In this case, the flow visualization over the horizontal plane indicates that the fresh air penetrates well inside the building up to the half of the building's depth. 


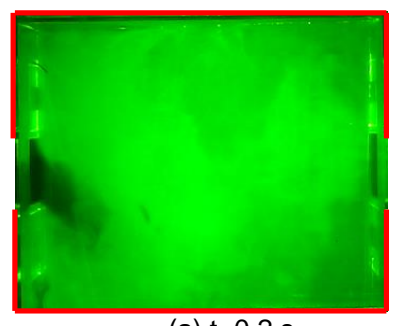

(a) $t=0.2 \mathrm{~s}$

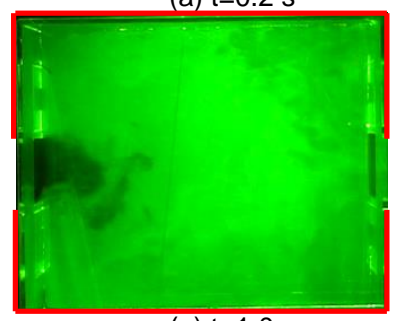

(e) $\mathrm{t}=1.0 \mathrm{~s}$

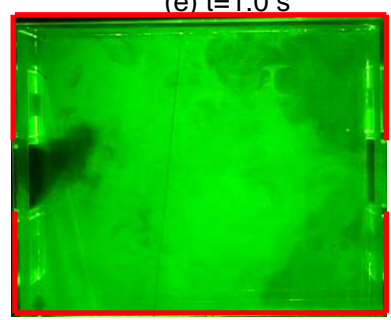

(i) $\mathrm{t}=1.8 \mathrm{~s}$

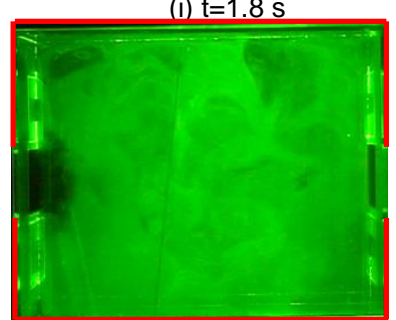

(m) $\mathrm{t}=2.6 \mathrm{~s}$

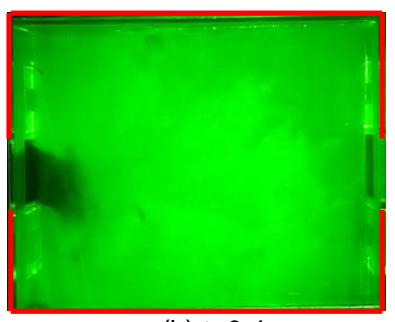

(b) $t=0.4 \mathrm{~s}$

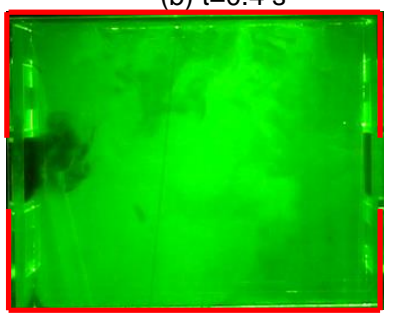

(f) $t=1.2 \mathrm{~s}$

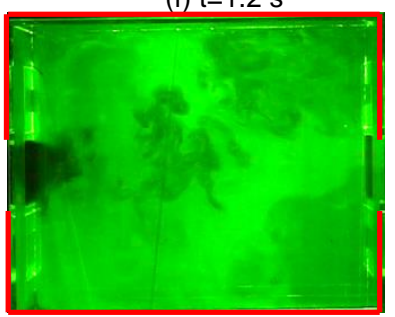

(i) $t=2.0 \mathrm{~s}$

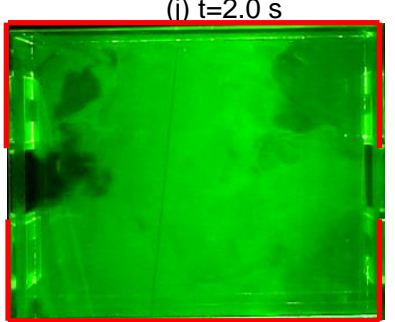

(n) $t=2.8 \mathrm{~s}$

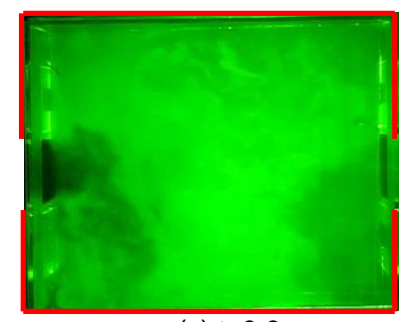

(c) $t=0.6 \mathrm{~s}$

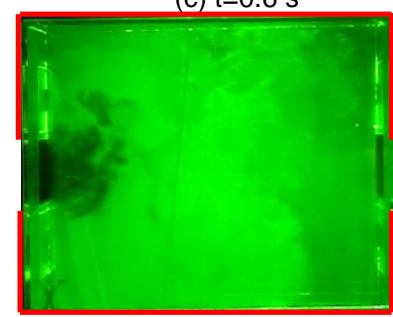

(a) $t=1.4 \mathrm{~s}$

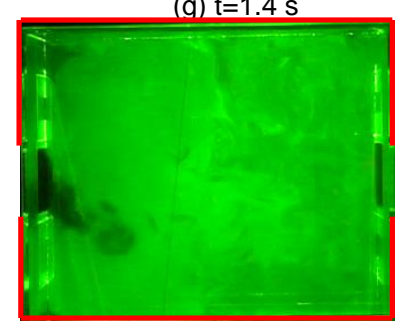

(k) $t=2.2 \mathrm{~s}$

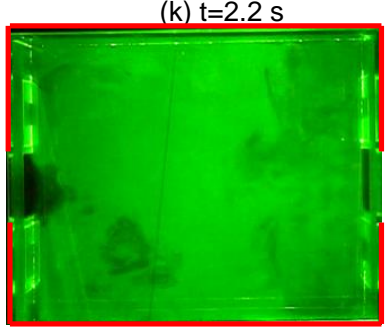

(o) $\mathrm{t}=3.0 \mathrm{~s}$

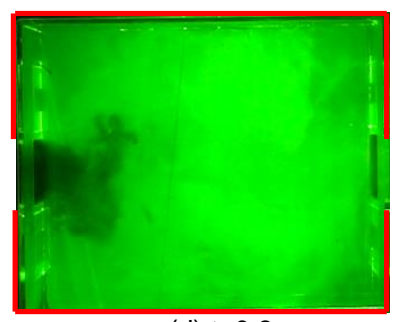

(d) $t=0.8 \mathrm{~s}$

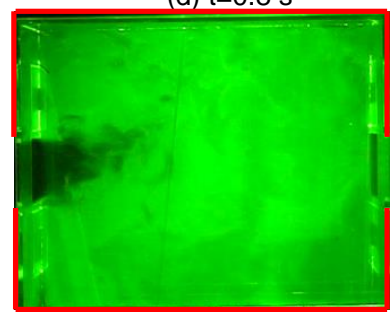

(h) $\mathrm{t}=1.6 \mathrm{~s}$

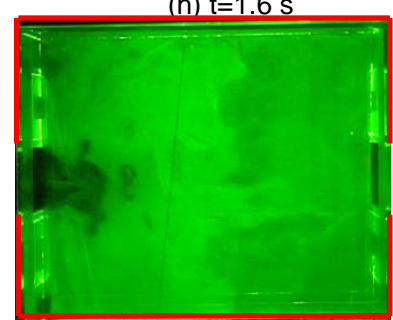

(I) $t=2.4 \mathrm{~s}$

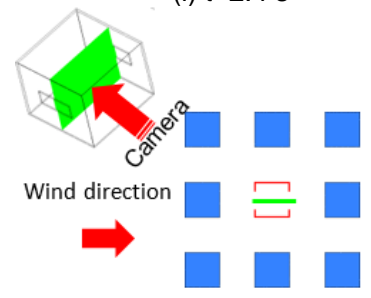

Figure 6 Flow visualization over the vertical central plane for $\lambda_{\mathrm{P}}=0.25$ against $\alpha=0^{\circ}$

The flow pattern over the vertical central plane inside the building for the case with $\lambda_{\mathrm{P}}=0.40$ is shown in Figure 7 against the wind angle of $\alpha=0^{\circ}$. The flow structure changes dramatically in this case in comparison to the case with $\lambda_{P}=0.25$. As shown in Figure $7(a)$, at the start of the visualization $(t=0.2 \mathrm{~s}$ ), the fresh air enters the building through the windward opening and then its vortices dissipate inside the building at $t=0.6 \mathrm{~s}$. After that, another wave of fresh air enters the building through the windward opening with a downward orientation and dilutes at $t=1.2 \mathrm{~s}$ (see Figure $7(f)$ ). At this time, another wave of fresh air enters the building surprisingly through the leeward opening. The incoming jet through the leeward opening has a very pronounced KelvinHelmholtz instability pattern and penetrates inside the building up to the internal side of the windward façade. This jet, named leeward jet hereinafter, oscillates with a frequency that is almost half the frequency of the windward jet, but it is significantly stronger than the windward jet in terms of the vortex structure and penetration length in the vertical view. The flapping (swiping) angle of the leeward jet is also lower than that of for the windward jet. 


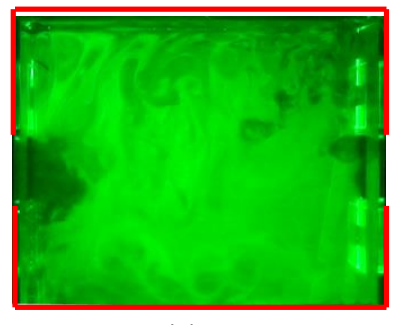

(a) $\mathrm{t}=0.2 \mathrm{~s}$

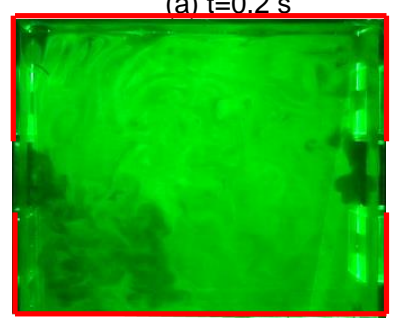

(e) $t=1.0 \mathrm{~s}$

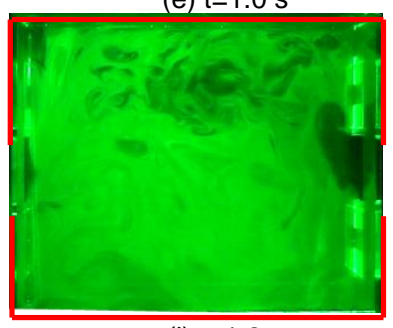

(i) $t=1.8 \mathrm{~s}$

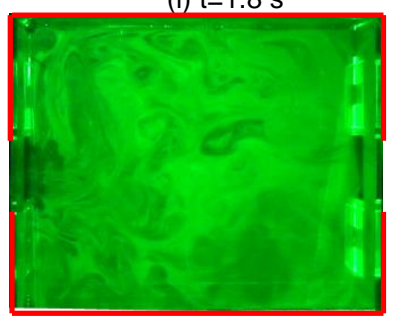

(m) $t=2.6 \mathrm{~s}$

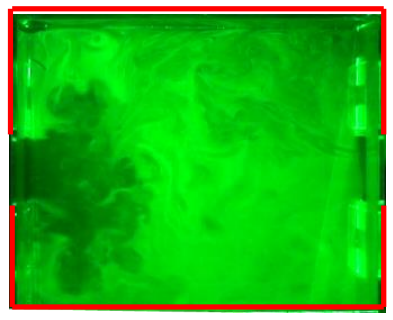

(b) $t=0.4 \mathrm{~s}$

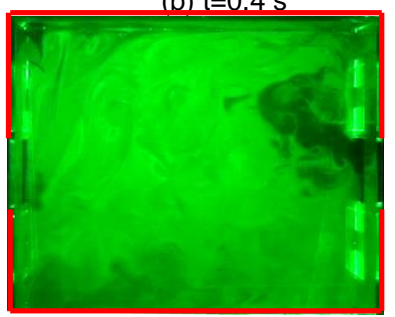

(f) $t=1.2 \mathrm{~s}$

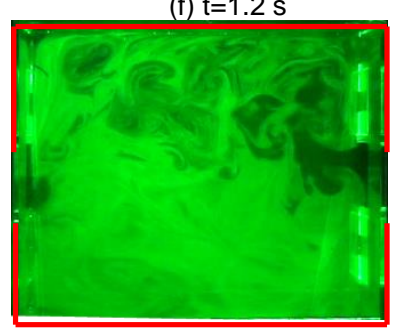

(j) $t=2.0 \mathrm{~s}$

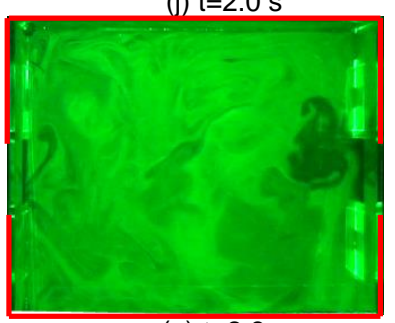

(n) $t=2.8 \mathrm{~s}$

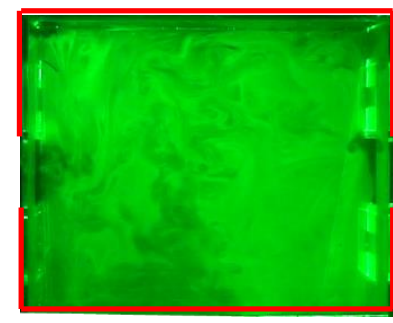

(c) $t=0.6 \mathrm{~s}$

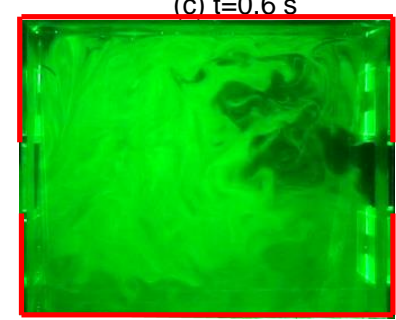

(g) $t=1.4 \mathrm{~s}$

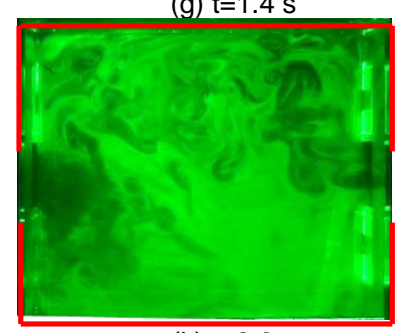

(k) $t=2.2 \mathrm{~s}$

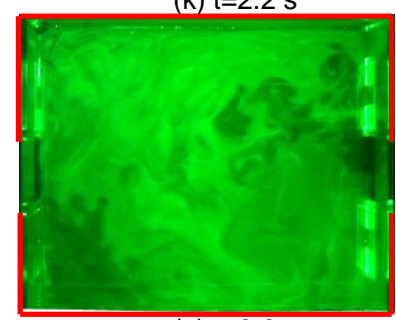

(o) $t=3.0 \mathrm{~s}$

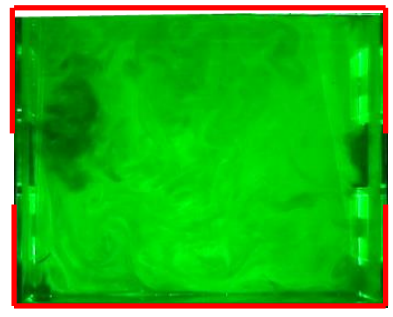

(d) $t=0.8 \mathrm{~s}$

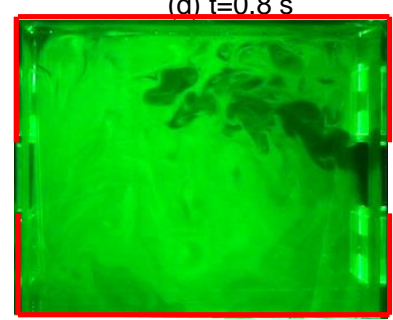

(h) $\mathrm{t}=1.6 \mathrm{~s}$

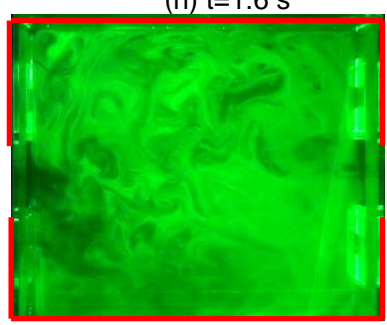

(I) $\mathrm{t}=2.4 \mathrm{~s}$

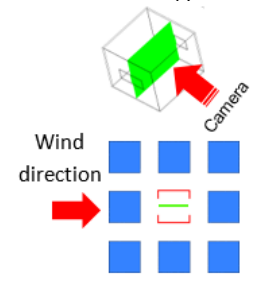

Figure 7 Flow visualization over the vertical central plane for $\lambda_{\mathrm{P}}=0.4$ against $\alpha=0^{\circ}$

As demonstrated in the flow visualization over the vertical plane (see Figure 7), the windward jet direction is nearly horizontal, hence, its transient pattern can be better visualized over the horizontal plane. The instantaneous airflow pattern over the horizontal plane inside the building is shown in Figure 8 for the case with the wind angle of $\alpha=0^{\circ}$ and planar area ratio of $\lambda_{\mathrm{P}}=0.40$. In contrast, the leeward jet pattern, which has an upward orientation, is not clearly observed over the horizontal plane. The windward jet oscillates in a noticeably wide range over the horizontal plane, but its frequency is lower that the frequency of the jet in the vertical plane. At the start of the visualization $(t=0.2 \mathrm{~s}$ ), the windward jet impinges on the left wall, then it moves toward the right one and impinges on it at $t=2.6 \mathrm{~s}$. The noticeable difference between the transient pattern of the windward and leeward jets over the vertical and horizontal planes reveals that they are generated by different mechanisms. 


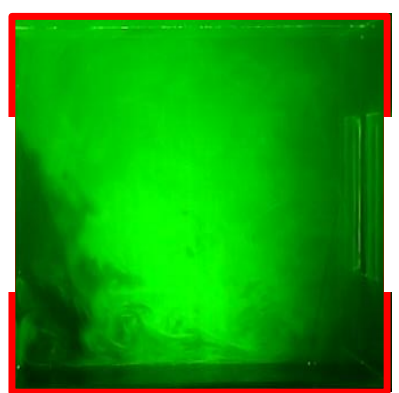

(a) $t=0.2 \mathrm{~s}$

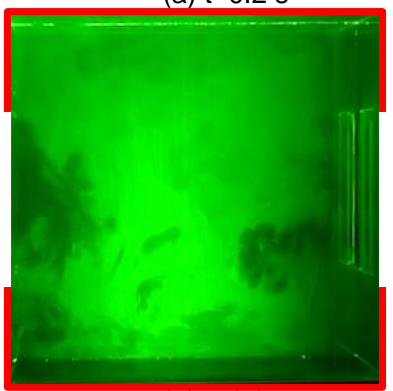

(e) $t=1.0 \mathrm{~s}$

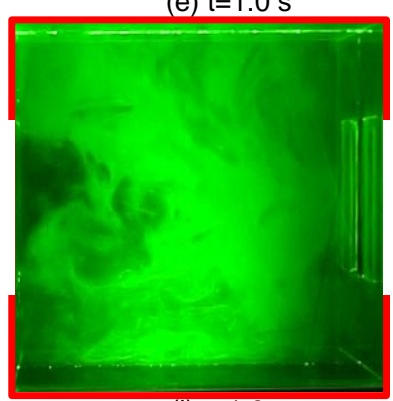

(i) $t=1.8 \mathrm{~s}$

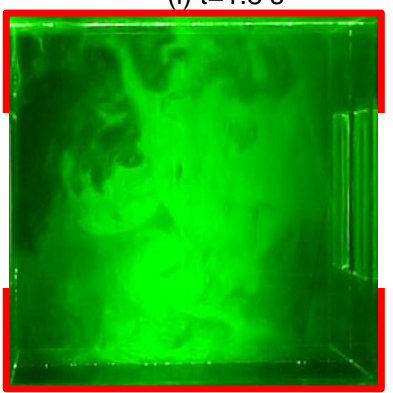

(m) $\mathrm{t}=2.6 \mathrm{~s}$

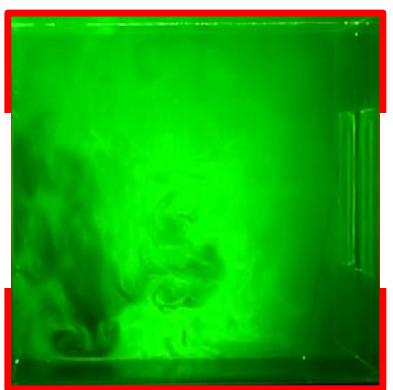

(b) $t=0.4 \mathrm{~s}$

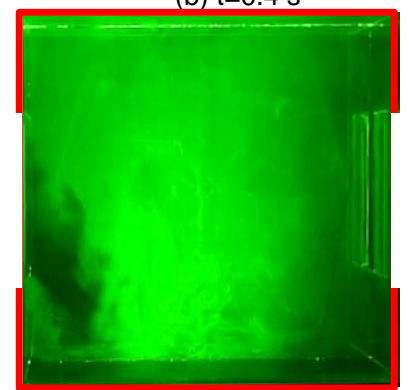

(f) $t=1.2 \mathrm{~s}$

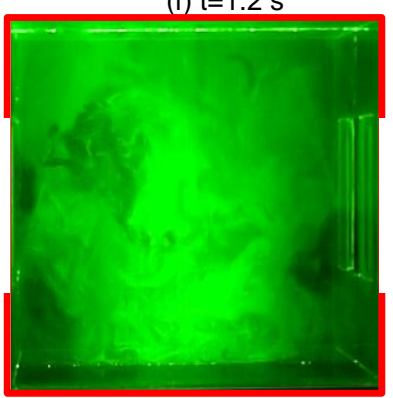

(i) $t=2.0 \mathrm{~s}$

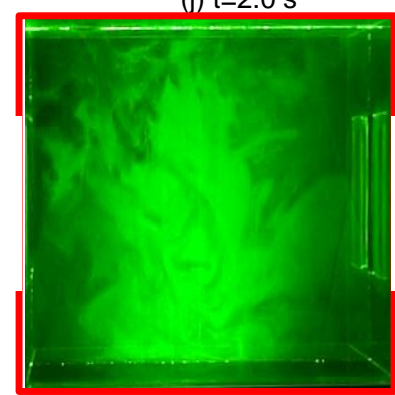

(n) $t=2.8 \mathrm{~s}$

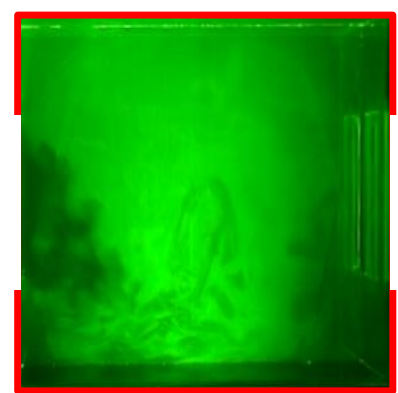

(c) $t=0.6 \mathrm{~s}$

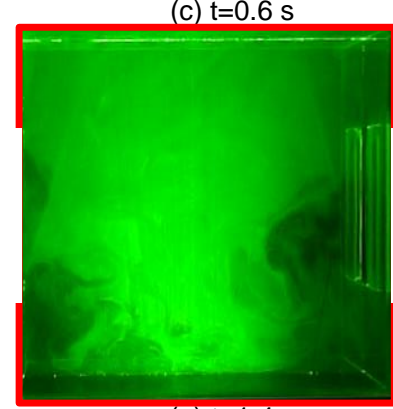

(g) $t=1.4 \mathrm{~s}$

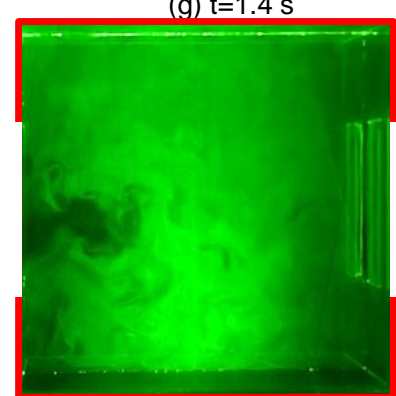

(k) $t=2.2 \mathrm{~s}$

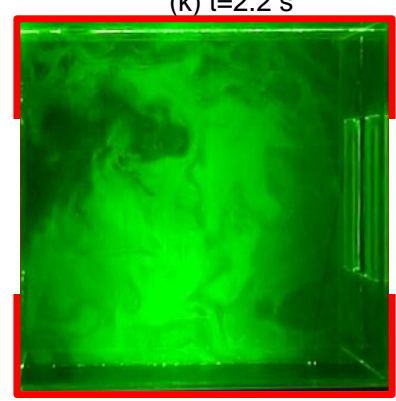

(o) $t=3.0 \mathrm{~s}$

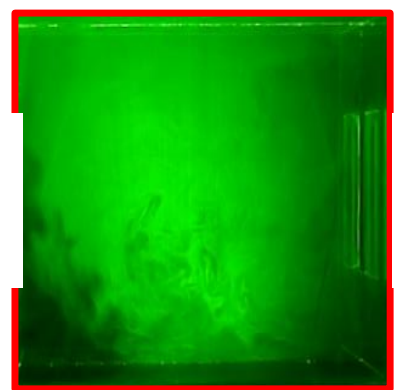

(d) $t=0.8 \mathrm{~s}$

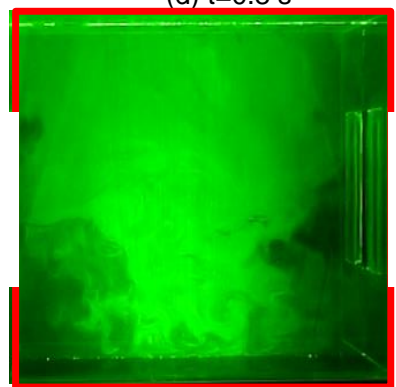

(h) $t=1.6 \mathrm{~s}$

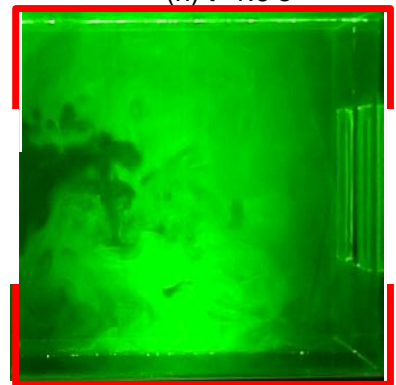

(I) $t=2.4 \mathrm{~s}$

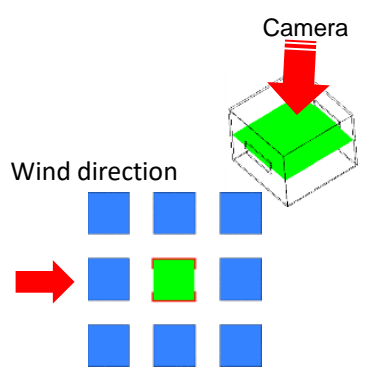

Figure 8 Flow visualization over the horizontal central plane for $\lambda_{\mathrm{P}}=0.40$ against $\alpha=0^{\circ}$

A series of flow visualizations were conducted over horizontal and vertical planes outside the building to investigate the formation mechanism of the windward and leeward jets in the upstream and downstream cavities around the target building. The quality of the outside flow visualizations was not well due to a rapid mixing between the released smoke and the wind tunnel fresh air. The outside visualizations are suitable to be seen as movie rather than time-history pictures. Hence, a schematic of the observed flow pattern around the cross-ventilated building with the planar area ratio $\lambda_{\mathrm{P}}=0.40$ is shown in Figure 9. In the horizontal plane located at the openings' height $\left(\frac{z}{H}=0.5\right)$, the street canyon flow is directed into the windward and leeward cavities from both sides and forms two recirculation zones with different sizes (see Figure 9(a)). The recirculating 
flow in the leeward cavity pushes the fresh air into the building through the leeward opening and generate the leeward jet that is shown in Figure 9(a). In contrast, the windward jet direction is in the opposite direction of the outdoor horizontal vortices. In the vertical view, as shown in Figure 9(b), the shear layer flow over the upstream building's roof enters the windward and leeward cavities and forms the vertical windward and leeward vortices. The leeward vortex stretches into the leeward cavity and pushes the fresh air into the building through the leeward opening and forms an upward oriented leeward jet. Considering the noticeable difference in the oscillating frequencies of the windward and leeward jets and the observation of the flow structure outside the building, it can be concluded that the generation of the windward jet is mostly contributed to the horizontal vortices, but the generation of the leeward jet is generally contributed to the vertical leeward vortex.

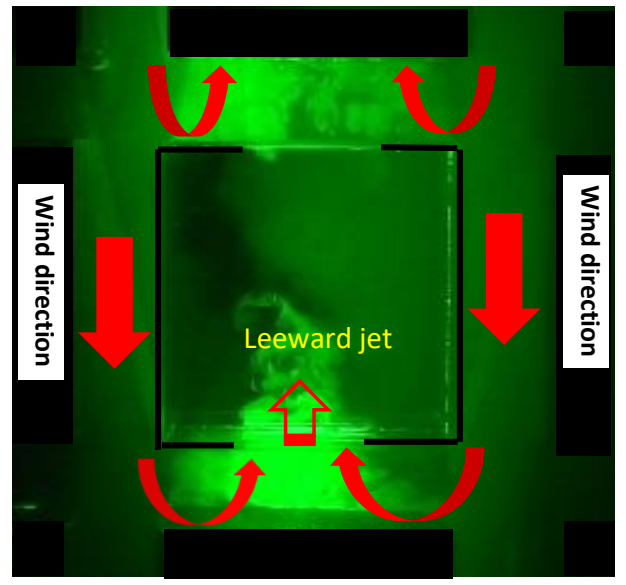

(a)

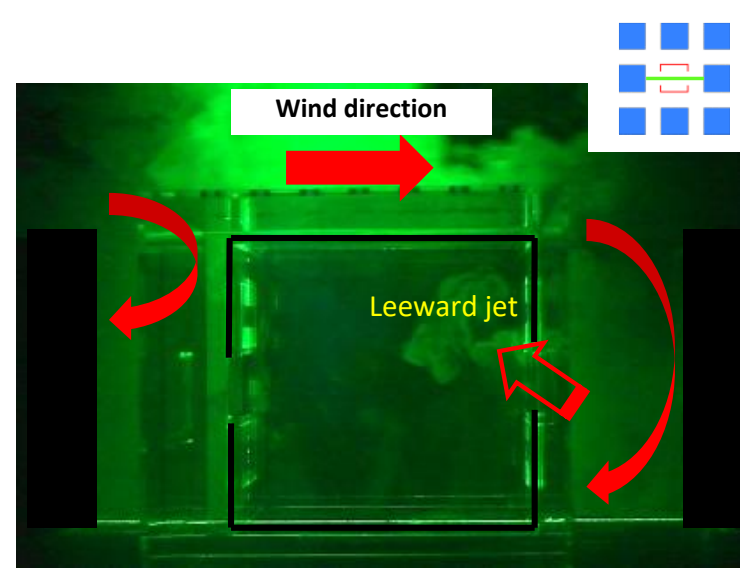

(b)

Figure 9 A schematic of flow pattern outside the cross-ventilated building over the (a) horizontal and (b) vertical planes for a planar area density of $\lambda_{\mathrm{P}}=\mathbf{0 . 4 0}$ against wind angle of $\alpha=0^{\circ}$

In Figure 10, the flow pattern is shown over the horizontal plane against the wind angle of $\alpha=60^{\circ}$ in the planar area ratio of $\lambda_{\mathrm{P}}=0.4$. The windward jet sweeps a narrow angle over the horizontal plane while it impinges directly on the right sidewall. In the leeward opening, the airflow leaves the building at $t=0.2 \mathrm{~s}$ until $t=0.8 \mathrm{~s}$ as shown in Figure 10(a). While the windward jet is entering into the building at $t=0.8 \mathrm{~s}$ (see Figure 10(d)), a pocket of fresh air enters the building through the leeward opening and then it disappears at $t=1.2 \mathrm{~s}$. Shortly after that, at $t=1.4 \mathrm{~s}$, the flow direction at leeward opening reverses and the airflow leaves the building through it. This process repeats again at $t=2.2 \mathrm{~s}$. 


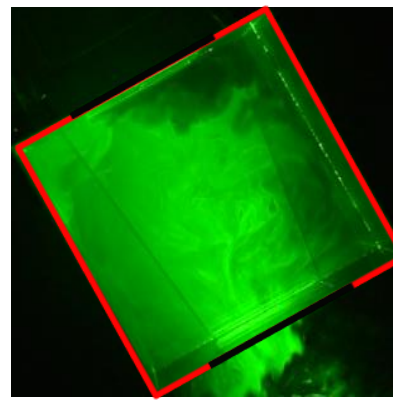

(a) $t=0.2 \mathrm{~s}$

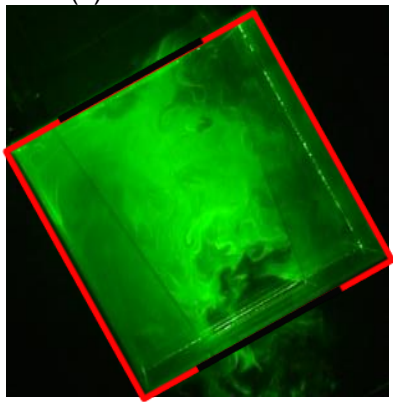

(e) $t=1.0 \mathrm{~s}$

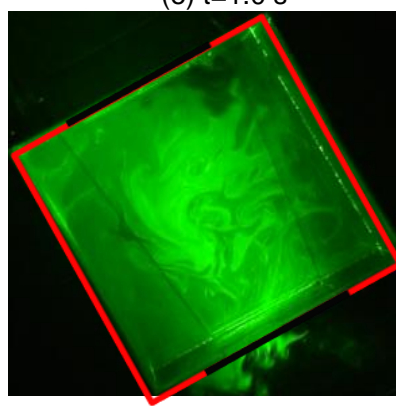

(i) $\mathrm{t}=1.8 \mathrm{~s}$

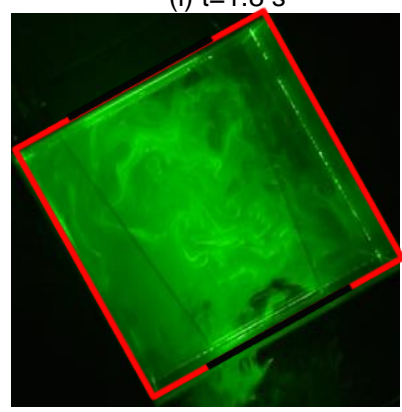

(m) $\mathrm{t}=2.6 \mathrm{~s}$

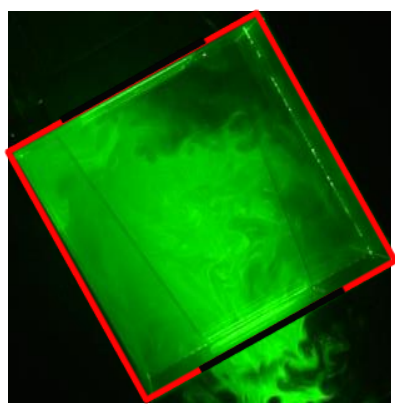

(b) $t=0.4 \mathrm{~s}$

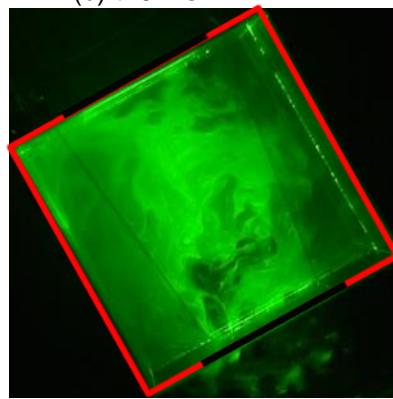

(f) $t=1.2 \mathrm{~s}$

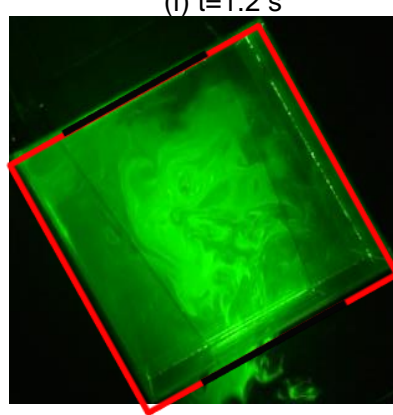

(j) $t=2.0 \mathrm{~s}$

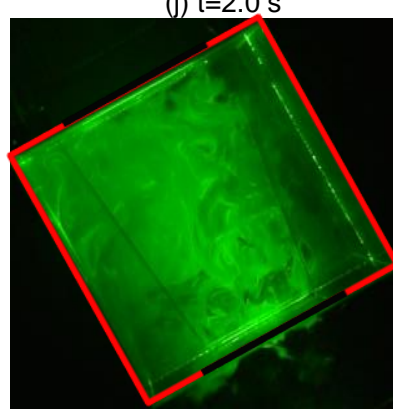

(n) $t=2.8 \mathrm{~s}$

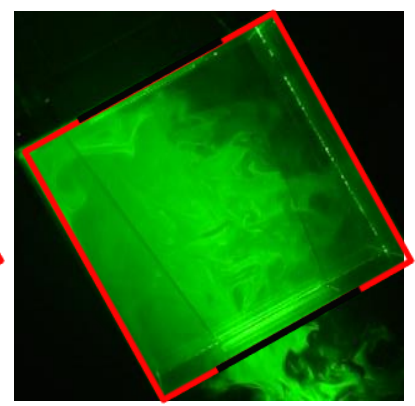

(c) $t=0.6 \mathrm{~s}$

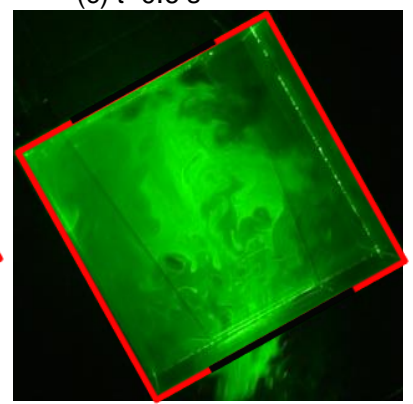

(g) $t=1.4 \mathrm{~s}$

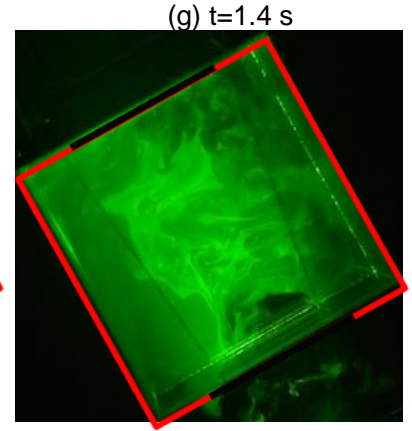

(k) $t=2.2 \mathrm{~s}$

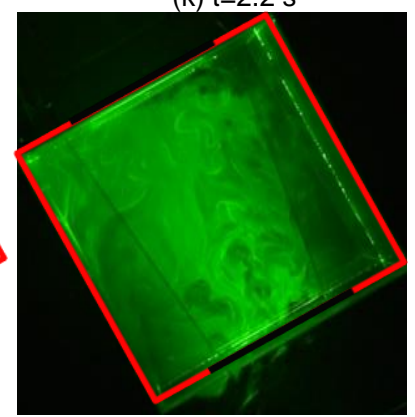

(o) $t=3.0 \mathrm{~s}$

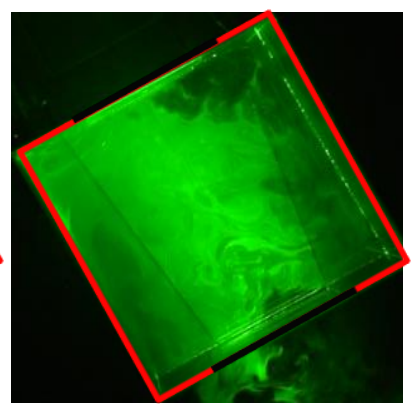

(d) $t=0.8 \mathrm{~s}$

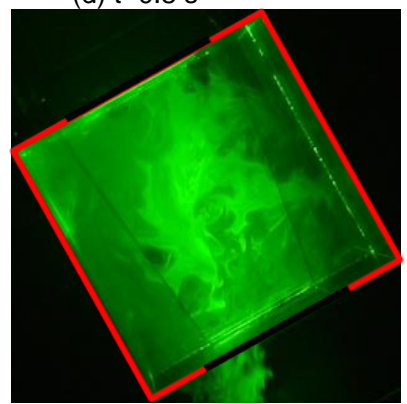

(h) $t=1.6 \mathrm{~s}$

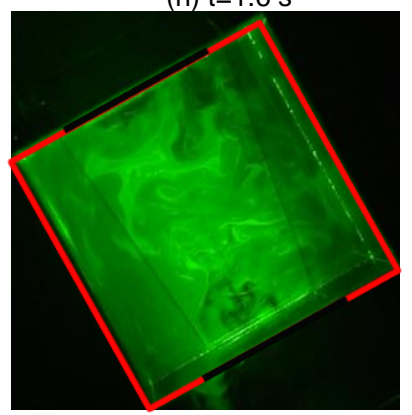

(I) $\mathrm{t}=2.4 \mathrm{~s}$ Camera

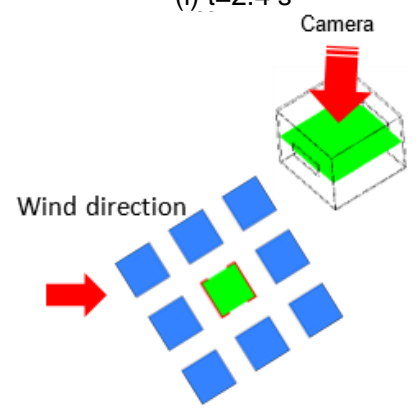

Figure 10 Flow visualization over the horizontal central plane for $\lambda_{\mathrm{P}}=0.40$ against $\alpha=60^{\circ}$

Flow visualization over the vertical central plane is shown in Figure 11 for a planar area ratio of $\lambda_{\mathrm{P}}=0.6$ against the wind angle of $\alpha=0^{\circ}$. The flow pattern is very similar to the case with $\lambda_{\mathrm{P}}=$ 0.4 , consisting of a highly transient leeward jet and a pronounced Kelvin-Helmholtz instability. The windward jet is very weak in this case and can be barely seen at $t=0.4 \mathrm{~s}$ and $t=2.4 \mathrm{~s}$ (see Figure 11(b) and Figure 11(I)). In contrary, the leeward jet is very strong over the vertical plane and penetrates well inside the building (see Figure 11(n) and Figure 11(0)). Despite the upward orientation of the leeward jet, which was similarly observed for $\lambda_{P}=0.40$, in the case of $\lambda_{P}=0.60$, the leeward jet oscillates over a wider range. The injection of the fresh air through the windward 
and leeward openings is very periodic. The windward and leeward jets have different pulsation frequencies but their frequencies remain constant over the time. The interaction between the windward and leeward jets makes a complex pattern of the flow inside the building that moves the bulk air in the streamwise direction during one pulse and then switches it in the reverse direction during the next pulse.

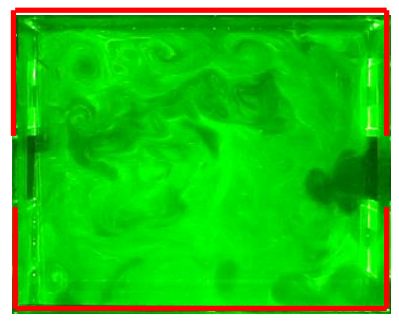

(a) $\mathrm{t}=0.2 \mathrm{~s}$

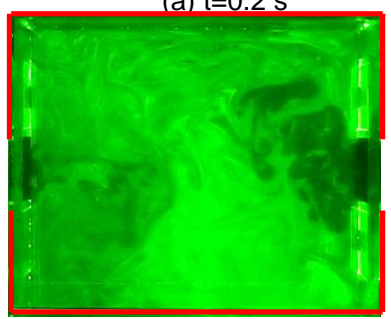

(e) $\mathrm{t}=1.0 \mathrm{~s}$

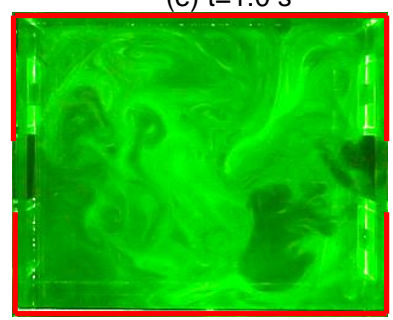

(i) $\mathrm{t}=1.8 \mathrm{~s}$

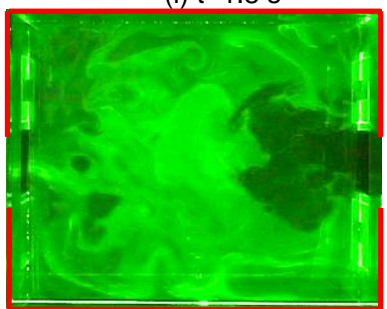

(m) $\mathrm{t}=2.6 \mathrm{~s}$

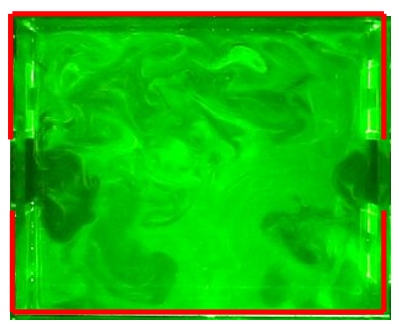

(b) $\mathrm{t}=0.4 \mathrm{~s}$

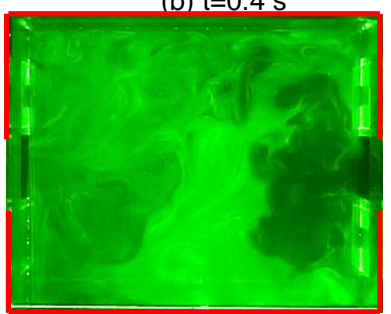

(f) $\mathrm{t}=1.2 \mathrm{~s}$

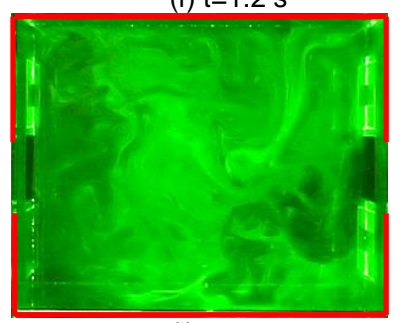

(j) $t=2.0 \mathrm{~s}$

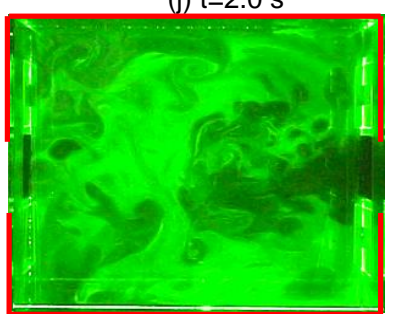

(n) $t=2.8 \mathrm{~s}$

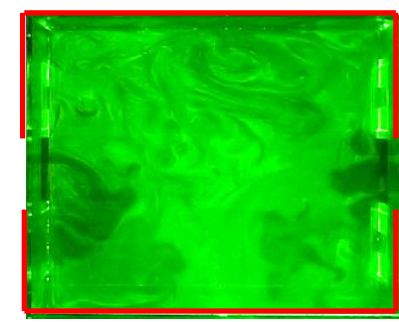

(c) $t=0.6 \mathrm{~s}$

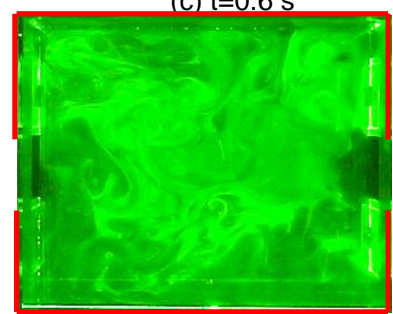

(g) $t=1.4 \mathrm{~s}$

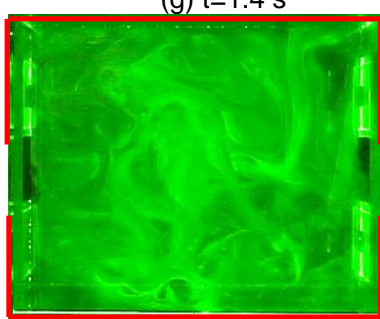

(k) $t=2.2 \mathrm{~s}$

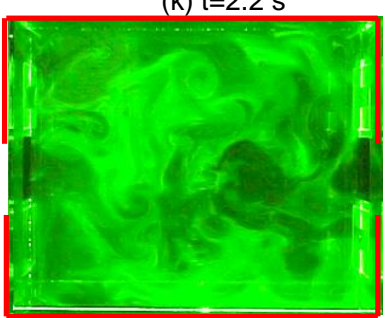

(o) $t=3.0 \mathrm{~s}$

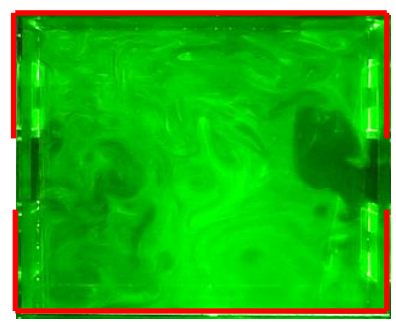

(d) $t=0.8 \mathrm{~s}$

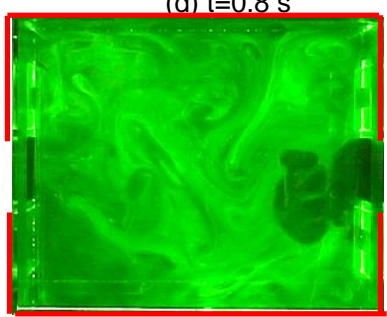

(h) $t=1.6 \mathrm{~s}$

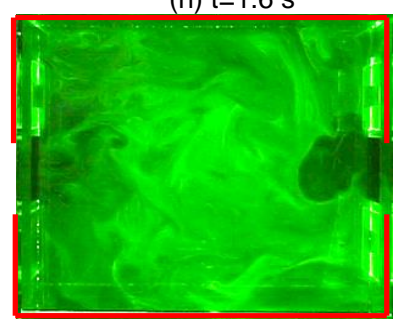

(I) $t=2.4 \mathrm{~s}$

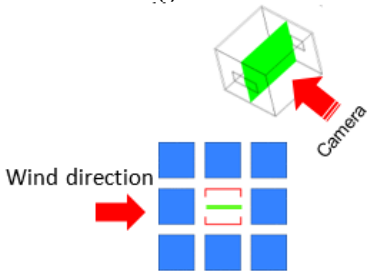

Figure 11 Flow visualization over the vertical central plane for $\lambda_{\mathrm{P}}=0.6$ against $\alpha=0^{\circ}$

The horizontal visualization for the case with the planar area ratio of $\lambda_{\mathrm{P}}=0.60$ against the wind angle of $\alpha=0^{\circ}$ is depicted in Figure 12. In this view, there is no trace of the windward jet, which shows how weak it is in the case of the highly-dense building arrangement. In contrast, the leeward jet is observed clearly with oscillations in a very wide range over the horizontal plane. Furthermore, over the horizontal plane the Kelvin-Helmholtz instability pattern can be clearly observed. 


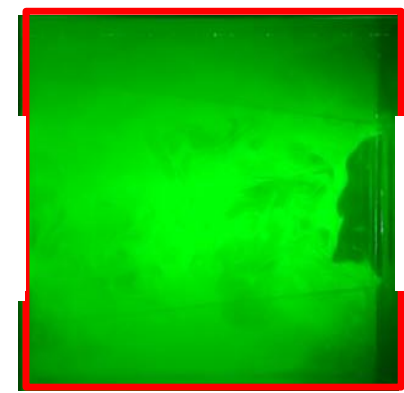

(a) $\mathrm{t}=0.2 \mathrm{~s}$

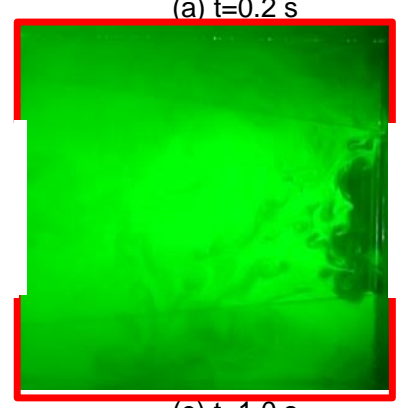

(e) $t=1.0$

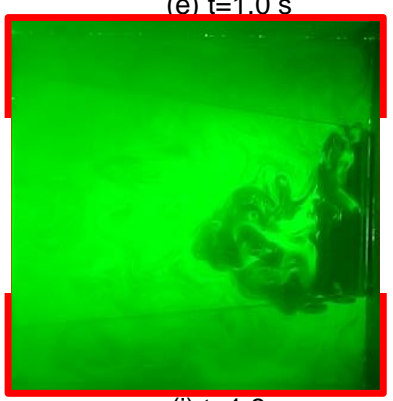

(i) $t=1.8 \mathrm{~s}$

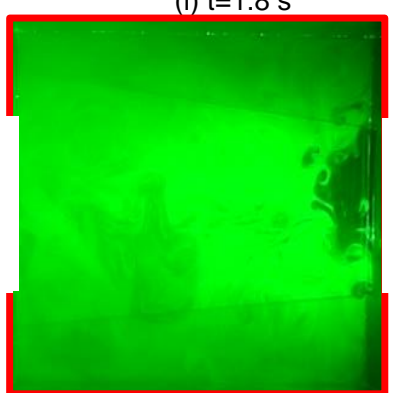

(m) $t=2.6 \mathrm{~s}$

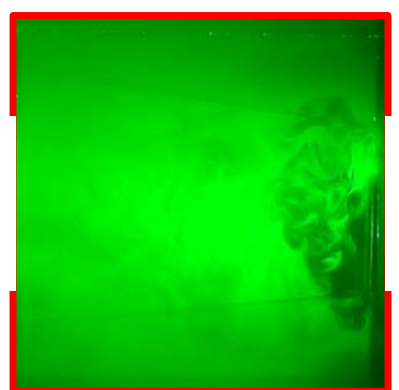

(b) $t=0.4 \mathrm{~s}$

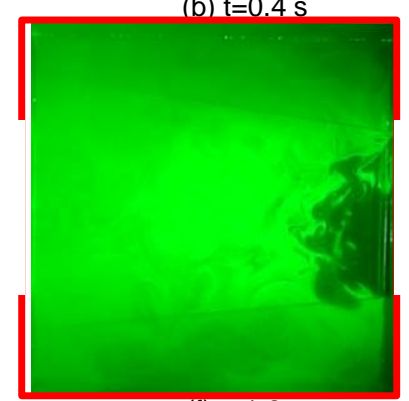

(f) $t=1.2 \mathrm{~s}$

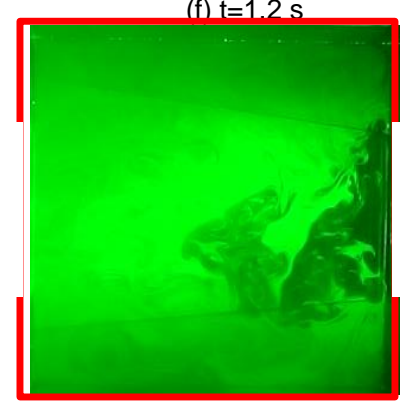

(i) $\mathrm{t}=2.0 \mathrm{~s}$

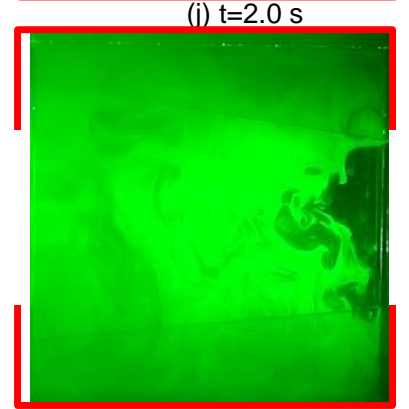

(n) $t=2.8 \mathrm{~s}$

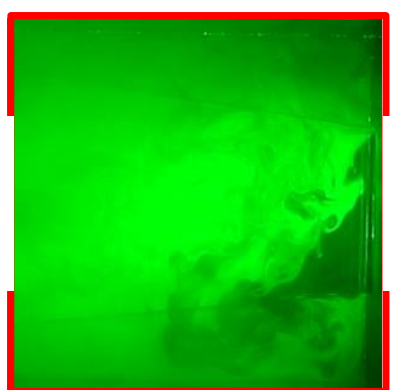

(c) $\mathrm{t}=0.6 \mathrm{~s}$

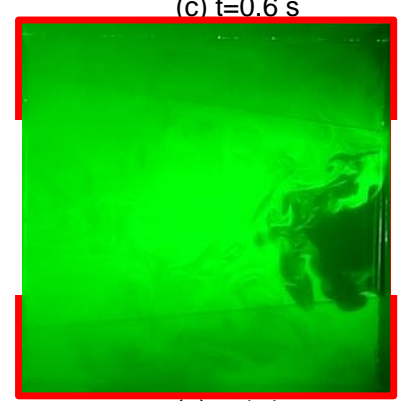

(a) $t=1.4 \mathrm{~s}$

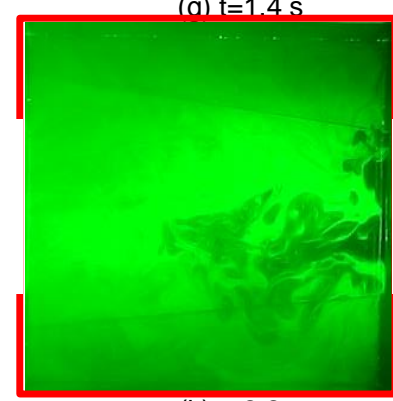

(k) $t=2.2 \mathrm{~s}$

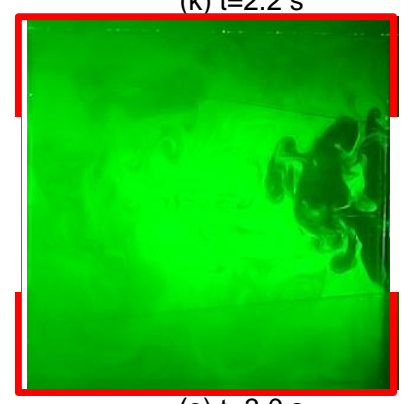

(o) $\mathrm{t}=3.0 \mathrm{~s}$

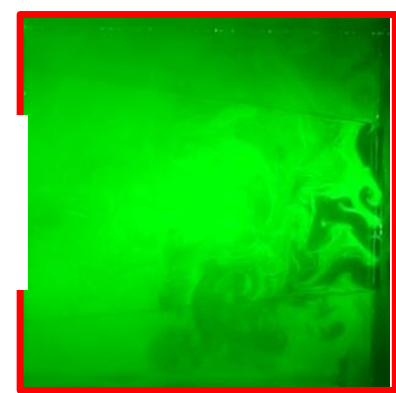

(d) $t=0.8 \mathrm{~s}$

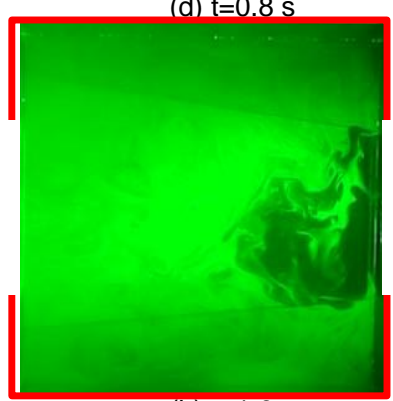

(h) $t=16 \mathrm{~s}$

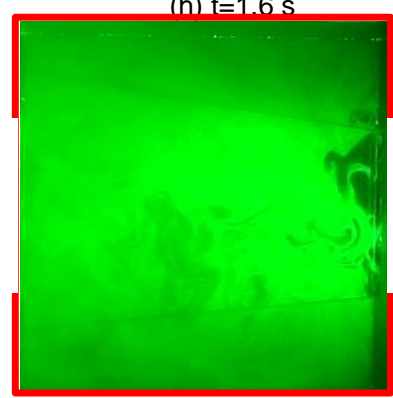

(I) $t=2.4 \mathrm{~s}$

Camera

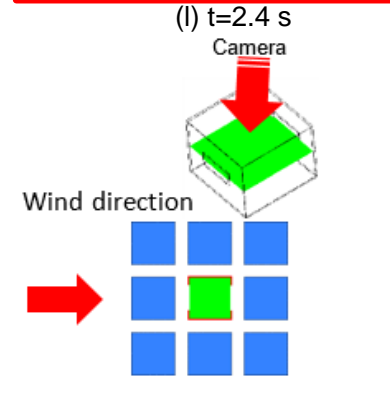

Figure 12 Flow visualization over the horizontal central plane for $\lambda_{\mathrm{P}}=0.60$ against $\alpha=0^{\circ}$

The flow visualization over the horizontal plane is shown in Figure 13 for the planar area ratio of $\lambda_{\mathrm{P}}=0.60$ against the wind angle of $\alpha=90^{\circ}$. The highly transient nature of the airflow can be seen in this figure where fresh air periodically enters the target building through the windward and leeward openings. At $t=0.2 \mathrm{~s}$, as shown in Figure 13(a), the airflow enters the building through the leeward opening and directly reaches to the sidewall. At $t=0.8 \mathrm{~s}$, as shown in Figure 13(d), another wave of fresh air enters the building through the windward opening. The frequencies of windward and leeward jet injections were not exactly the same and both jets were occasionally impacted by each other. It seems that the disturbance generated via some measurement 
apparatus (e.g. tubing for the tracer gas), which were installed on the turntable located upstream of the buildings can result in such unequal jet frequencies. Inside the cross-ventilated building and far from the location of jets' collision, the airflow is trapped and forms a weak recirculation region over the horizontal plane.

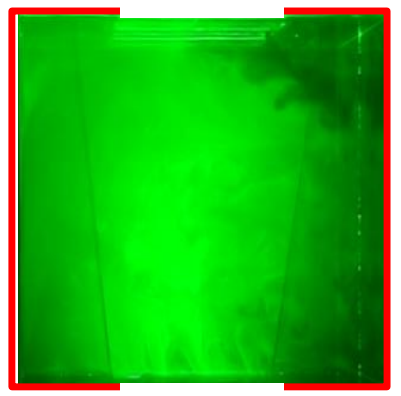

(a) $\mathrm{t}=0.2 \mathrm{~s}$

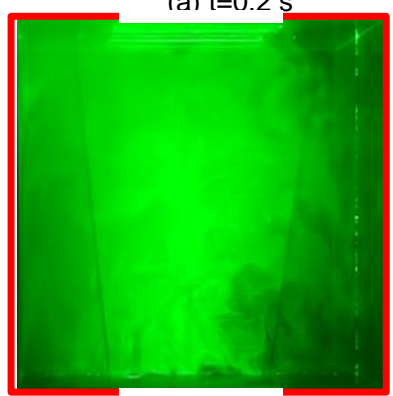

(e) $t=1.0 \mathrm{~s}$

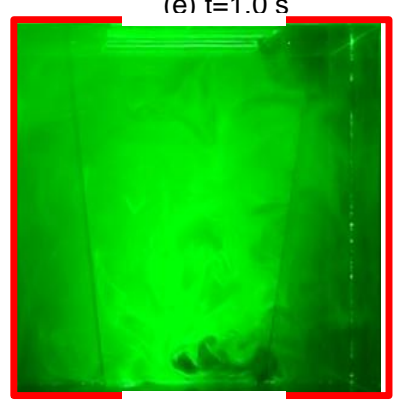

(i) $\mathrm{t}=1.8 \mathrm{~s}$

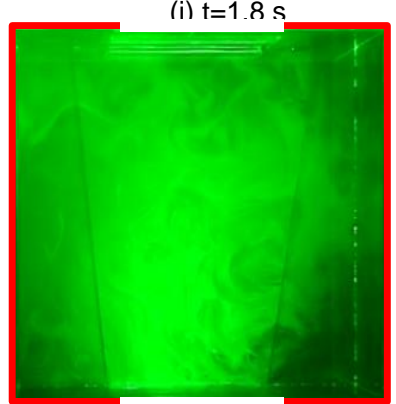

(m) $\mathrm{t}=2.6 \mathrm{~s}$

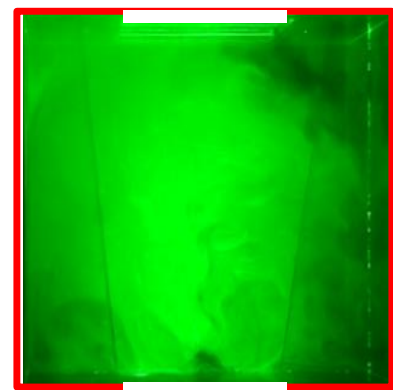

(b) $t=0.4 \mathrm{~s}$

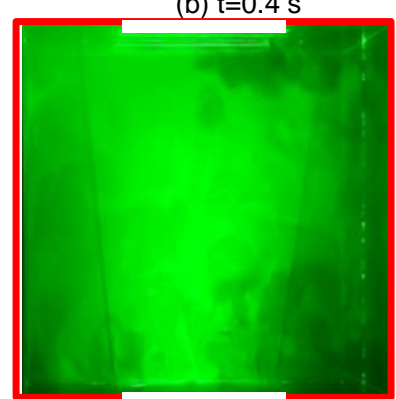

(f) $\mathrm{t}=1.2 \mathrm{~s}$

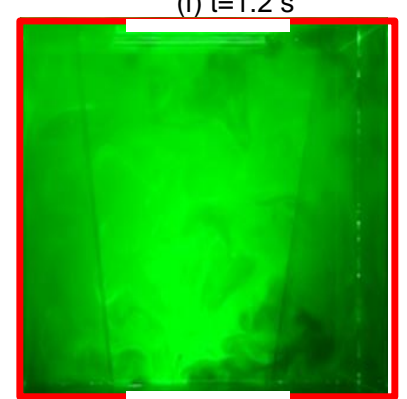

(i) $\mathrm{t}=2.0 \mathrm{~s}$

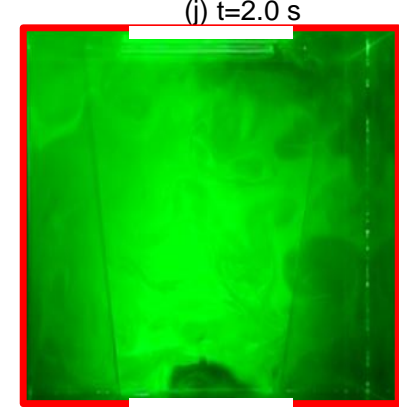

(n) $\mathrm{t}=2.8 \mathrm{~s}$

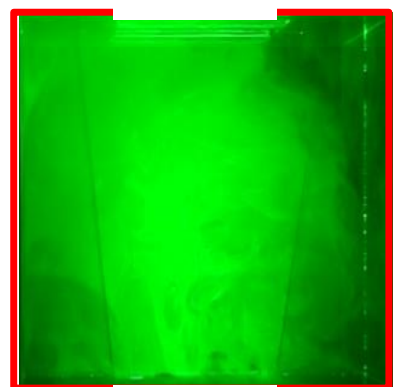

(c) $t=0.6 \mathrm{~s}$

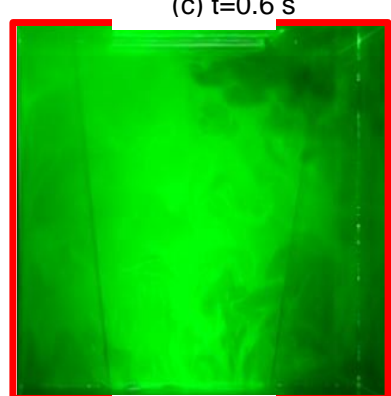

(g) $t=1.4 \mathrm{~s}$

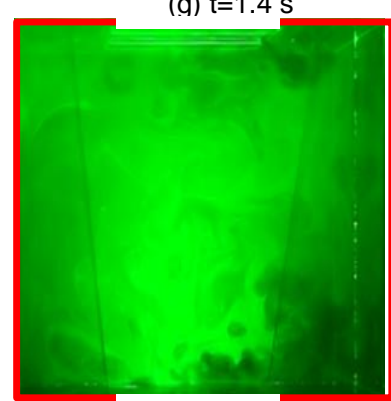

(k) $t=2.2 \mathrm{~s}$

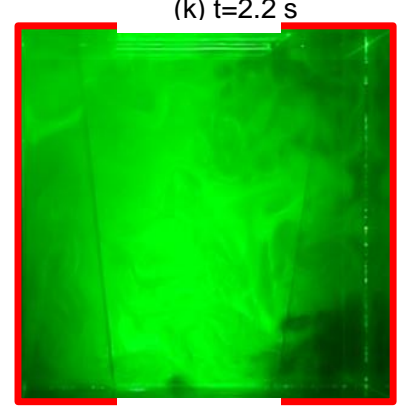

(o) $t=3.0 \mathrm{~s}$

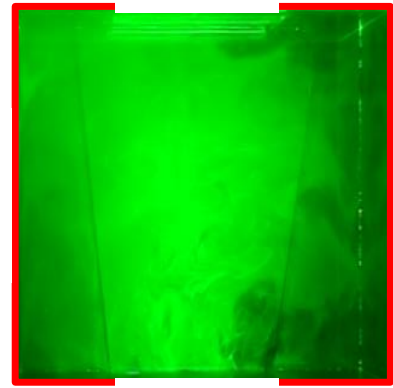

(d) $\mathrm{t}=0.8 \mathrm{~s}$

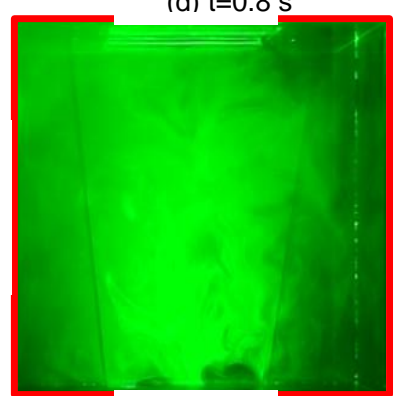

(h) $t=1.6 \mathrm{~s}$

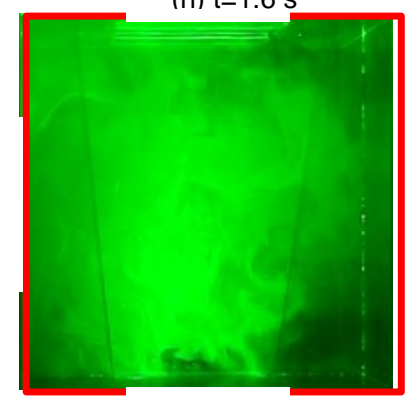

(I) $t=2.4 \mathrm{~s}$

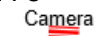

Wind direction

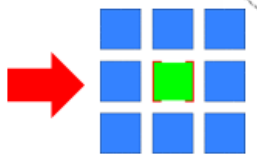

Figure 13 Flow visualization over the horizontal central plane for $\lambda_{\mathrm{P}}=0.60$ against $\alpha=90^{\circ}$ 


\section{Surface wind pressure measurements}

Variation of the surface-averaged wind pressure difference coefficients (eq. 3, 4, and 5) against different wind angles with different planar area ratios are shown in Figure 14. Measurement results were obtained for the unsheltered building $\left(\lambda_{P}=0.0\right)$ and sheltered building scenarios. The moderately-dense scenario $\left(\lambda_{\mathrm{P}}=0.25\right)$ is further shown to compare with the cases of highlydense building configurations of $\lambda_{P}=0.4$ and $\lambda_{P}=0.6$.

The pressure difference coefficient across the windward and leeward façades $\left(\Delta C_{P}^{w w}, \Delta C_{P}^{l w}\right)$ and the total pressure difference coefficient across the building $\left(\Delta C_{P}^{\text {total }}\right)$ measured for the unsheltered building case $\left(\lambda_{P}=0.0\right)$ are significantly higher than the measured values for all sheltered cases against different wind angles. The reduced velocity around the buildings due to the sheltering condition of the surrounding buildings results in a lower wind surface pressure over the building surfaces in the sheltered building cases.

For the unsheltered building, results of the total pressure difference coefficient across the building $\left(\Delta C_{P}^{\text {total}}\right)$ are compared with the experimental measurements by (Quan et al., 2007), who measured sealed-body wind pressure distribution over a building with similar geometry in the atmospheric wind tunnel at Tokyo Polytechnic University. Very close agreements between the two experiments is observed against all wind angles. The small deviations between the two results are due to the fact that in (Quan et al., 2007) over 48 pressure taps were utilized over the building façades while in current experiment only four pressure taps are installed around the openings.

The trend of the pressure difference coefficients' variation against wind angles is completely different for each urban configuration with a clear dependency on the planar area ratio. As shown in Figure 14(a), for the unsheltered building scenario, the $\Delta C_{P}^{\text {total }}$ rises slightly from 0.912 to 0.977 when the wind angle increases from $0^{\circ}$ to $15^{\circ}$. It then decreases uniformly and reaches to a value of 0.06 against the wind angle of $90^{\circ}$. The values of $\Delta C_{P}^{w w}$ and $\Delta C_{P}^{l w}$ show same trends in the unsheltered case.

When the planar area ratio rises to $\lambda_{\mathrm{P}}=0.25$, the patterns of the pressure difference coefficients are more sensitive to the wind angle variation. The $\Delta C_{P}^{\text {total }}$ rises noticeably from 0.171 to 0.331 when the wind angle increases from $0^{\circ}$ to $15^{\circ}$. It remains almost constant against the wind angles of $30^{\circ}$ and $45^{\circ}$, then it declines rapidly to $\Delta C_{P}^{\text {total }}=0.163$ when the wind angle rises further to $60^{\circ}$ and remains constant up to $\alpha=75^{\circ}$. The same pattern can be observed for $\Delta C_{P}^{w w}$ and $\Delta C_{P}^{l w}$ while the measured values are about the half of those measured for the $\Delta C_{P}^{\text {total }}$. All pressure difference coefficients are about zero against the wind angle of $90^{\circ}$.

When the planar area ratio increases to $\lambda_{P}=0.40$, the pressure difference coefficients further decrease to almost half the values measured for $\lambda_{P}=0.25$ (see Figure 14(c)). In this case, the total pressure difference across the building, windward and leeward openings are very low at the wind angle of $\alpha=0^{\circ}$ and respectively recorded to be $\Delta C_{P}^{t o t a l}=0.026, \Delta C_{P}^{w w}=0.021$, and $\Delta C_{P}^{l w}=$ 0.006 . When the wind angle further increases to $\alpha=15^{\circ}$, these values significantly rise to $\Delta C_{P}^{\text {total }}=0.182, \Delta C_{P}^{w w}=0.098$, and $\Delta C_{P}^{l w}=0.084$, and then remain almost constant up to the 
wind angle of $\alpha=45^{\circ}$. Then, they steadily decline to $\Delta C_{P}^{\text {total }}=-0.031, \Delta C_{P}^{w w}=-0.003$, and $\Delta C_{P}^{l w}=-0.028$ against the wind angle of $\alpha=90^{\circ}$.

Variation of the pressure difference coefficients of the densest building arrangement with $\lambda_{\mathrm{P}}=$ 0.60 shows a completely different pattern in comparison with other building arrangements (see Figure $14(\mathrm{~d}))$. At the normal wind angle $\left(\alpha=0^{\circ}\right)$, the total pressure difference coefficient is negative with a value of $\Delta C_{P}^{\text {total }}=-0.047$, which confirm the observed clear leeward jet during the flow visualization (see Figure 11 and Figure 12). At this wind angle, the windward and leeward pressure difference coefficients are respectively $\Delta C_{P}^{w w}=-0.048$ and $\Delta C_{P}^{l w}=0.001$. When the wind angle increases, these pressure difference coefficients elevate uniformly and reach to their maximum values of $C_{P}^{\text {total }}=0.098, \Delta C_{P}^{w w}=0.061$, and $\Delta C_{P}^{l w}=0.036$ at a wind angle of $\alpha=60^{\circ}$. Then, all pressure difference coefficients fall to a value near zero against the wind angle of $\alpha=$ $90^{\circ}$.

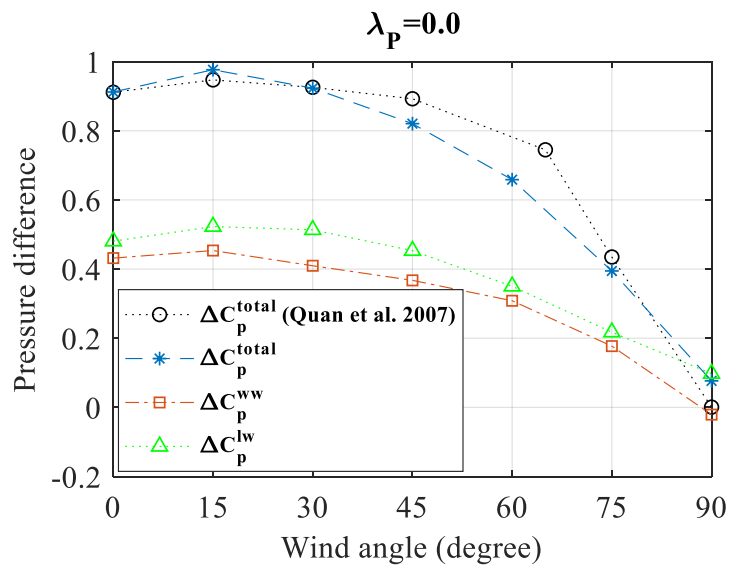

(a)

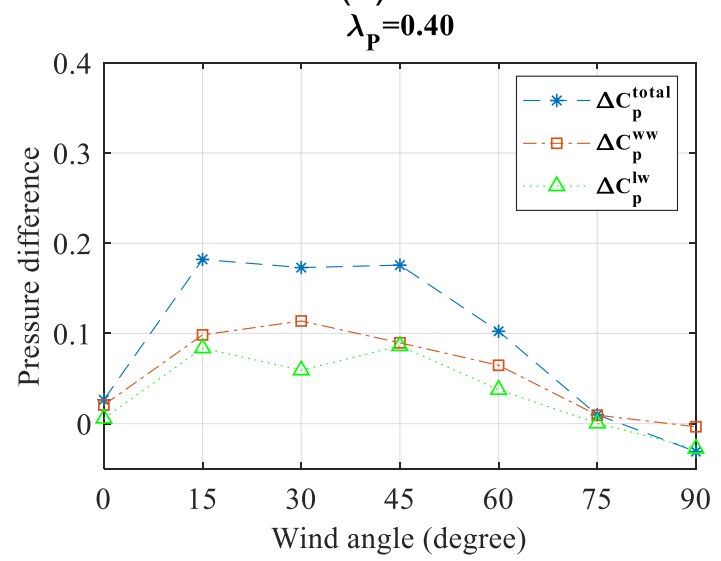

(c)

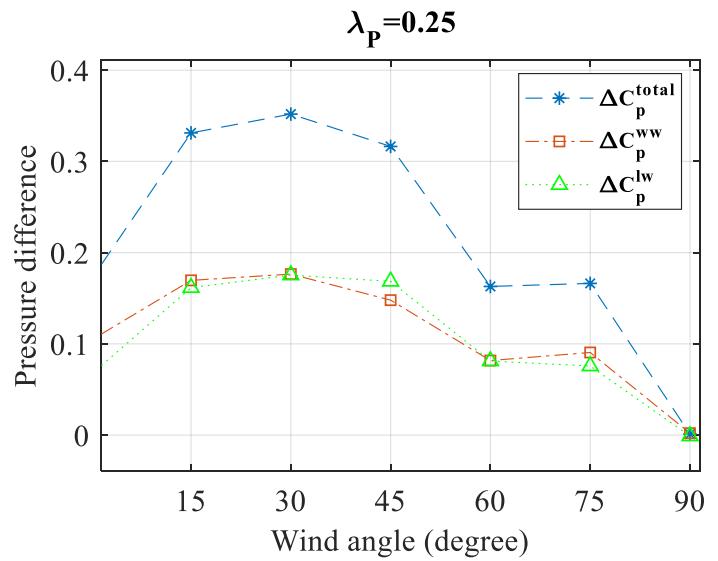

(b)

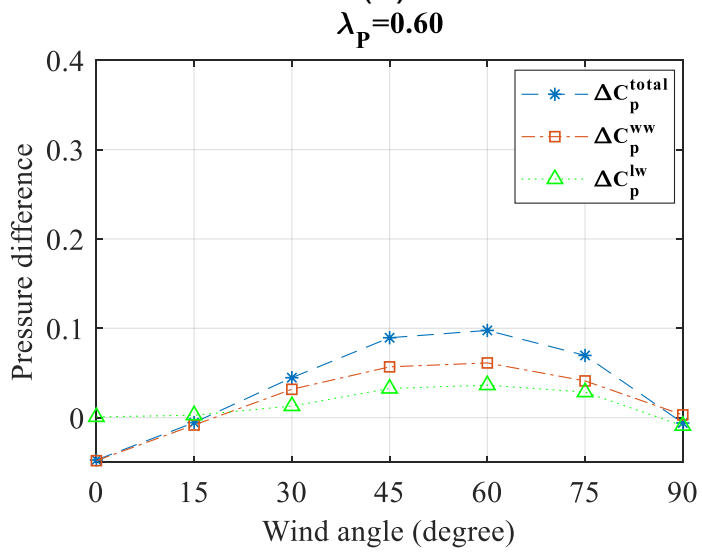

(d)

Figure 14 Variation of the surface averaged pressure difference against different wind angles for (a) $\lambda_{P}=0$ (unsheltered building), (b) $\lambda_{\mathrm{P}}=0.25$, (c) $\lambda_{\mathrm{P}}=0.40$, (d) $\lambda_{\mathrm{P}}=0.60$

\section{Airflow rate measurements}

The non-dimensional cross-ventilation airflow rate $\left(q_{c v}\right)$ is calculated as shown below in which $A_{\text {opening }}$ the area of the windward is opening: 


$$
q_{c v}=\frac{q_{\text {opening }}}{U_{H} A_{\text {opening }}}
$$

The variation of $q_{c v}$ is shown in Table 1 for different building configurations against different wind angles. The measured values for the highly-dense urban configurations $\left(\lambda_{P}=0.4, \lambda_{P}=0.6\right)$ are further compared with the unsheltered building case $\left(\lambda_{P}=0.0\right)$ and the moderately-dense case $\left(\lambda_{P}=0.25\right)$. As expected, for the case of the unsheltered building $\left(\lambda_{P}=0.0\right)$, the crossing airflow rates are higher than the sheltered cases against all wind angles. Against the wind angle of $0^{\circ}$ and $15^{\circ}$, the crossing airflow rates are very close with values of $q_{c v}=0.42$ and $q_{c v}=0.43$, respectively. Then, $q_{c v}$ slightly decreases until reaches to 0.38 against the wind angle of $15^{\circ}$ while it starts to decrease rapidly to 0.23 and 0.25 against the wind angle of $75^{\circ}$ and $90^{\circ}$, respectively. The measured value of $q_{c v}$ against the wind angle of $90^{\circ}$ is affected by the limitations of the tracer gas method because of the frequently entering fresh air from both windward and leeward openings similar to the case shown in Figure 13. It should be again mentioned that the fully-mixed condition of the tracer gas method, required for an accurate airflow measurement, is not fully met when the airflow enters the building through both openings. This is also the case for the sheltered building conditions, specifically for the highly-dense configurations of $\lambda_{P}=0.40$ and $\lambda_{P}=0.60$.

When the planar area ratio increases to $\lambda_{\mathrm{P}}=0.25$, the average crossing mass flow rate shows a significant reduction in relation with the measured values for the unsheltered case against all wind angles. In this case, the measured values of $q_{c v}$ are respectively $0.12,0.15,0.16,0.13,0.10$, 0.09 , and 0.07 against the wind angles of $0^{\circ}, 15^{\circ}, 30^{\circ}, 45^{\circ}, 60^{\circ}, 75^{\circ}$, and $90^{\circ}$. As it can be seen, the maximum $q_{c v}$ is measured against the wind angles between $15^{\circ}$ and $30^{\circ}$ while in this range the measured total pressure difference across the building is also in its maximum value (see Figure 14(b)).

For the buildings arrangement with $\lambda_{\mathrm{P}}=0.40$, the airflow rate variation against different wind angles shows a similar pattern with the case with $\lambda_{\mathrm{P}}=0.25$. The airflow rate is $q_{c v}=0.08$ against the wind angle of $\alpha=0^{\circ}$, which is significantly lower than the measured value for $\lambda_{\mathrm{P}}=0.25$. When the wind angle rises to $15^{\circ}$, the crossing airflow rate increases to $q_{c v}=0.15$, which is surprisingly equal to the one measured for $\lambda_{P}=0.25$. Similarly against other wind angles, the measured airflow rates at $\lambda_{P}=0.40$ are almost equal with those measured at $\lambda_{P}=0.25$. As observed in the flow visualization section (see Figure 8, Figure 9, and Figure 10), in the case of $\lambda_{P}=0.40$, a noticeable amount of fresh air enters the building through the leeward opening, which reduces the tracer gas concentration near the sampling tube and negatively impacts the accuracy of the tracer gas method.

For the case with the highest planar area ratio $\left(\lambda_{P}=0.6\right)$, the crossing airflow rates show a noticeable reduction against the low wind angles of $0^{\circ}, 15^{\circ}$, and $30^{\circ}$ with the values of $0.06,0.08$, and 0.09 , respectively. At the higher wind angles, the crossing airflow rates become very close to the measured values for $\lambda_{P}=0.25$ and $\lambda_{P}=0.4$. As shown in flow visualization, in the case of highly-dense buildings arrangement, a very strong lee vortex exists in the leeward cavity, which injects a significant amount of fresh air into the building through the leeward opening (see Figure 11, Figure 12, and Figure 13). This phenomenon has adverse effects on the accuracy of the airflow rate measurement by the tracer gas method as mentioned earlier. 
Table 1 The crossing airflow rate $\left(\boldsymbol{q}_{c v}\right)$ against different wind angles and planar area ratios

\begin{tabular}{cccccccc}
$\boldsymbol{q}_{c v}$ & $\boldsymbol{\alpha}=\mathbf{0}^{\circ}$ & $\boldsymbol{\alpha}=\mathbf{1 5}^{\circ}$ & $\boldsymbol{\alpha}=\mathbf{3 0}^{\circ}$ & $\boldsymbol{\alpha}=\mathbf{4 5}^{\circ}$ & $\boldsymbol{\alpha}=\mathbf{6 0}^{\circ}$ & $\boldsymbol{\alpha}=\mathbf{7 5}^{\circ}$ & $\boldsymbol{\alpha}=\mathbf{9 0}^{\circ}$ \\
\hline $\boldsymbol{\lambda}_{\mathrm{P}}=\mathbf{0 . 0}$ & 0.42 & 0.43 & 0.40 & 0.40 & 0.38 & 0.23 & 0.25 \\
$\boldsymbol{\lambda}_{\mathbf{P}}=\mathbf{0 . 2 5}$ & 0.12 & 0.15 & 0.16 & 0.13 & 0.10 & 0.10 & 0.07 \\
$\boldsymbol{\lambda}_{\mathbf{P}}=\mathbf{0 . 4 0}$ & 0.08 & 0.15 & 0.15 & 0.13 & 0.12 & 0.09 & 0.09 \\
$\boldsymbol{\lambda}_{\mathbf{P}}=\mathbf{0 . 6 0}$ & 0.06 & 0.08 & 0.09 & 0.10 & 0.10 & 0.08 & 0.05
\end{tabular}

\section{Conclusions}

A series of wind tunnel measurements were conducted to study the cross-ventilation through generic form low-rise buildings. Buildings were placed in a regular arrangement with very dense urban configurations exposed against different wind angles. Airflow distribution around and inside the cross-ventilated target building was studied using a smoke generator and a high-speed camera for flow visualization. Furthermore, the crossing airflow rate through the cross-ventilated target building was measured using the tracer gas method while the distribution of wind surface pressure coefficients over the building surfaces were measured against different wind angles in different urban planar areas ratios.

The experimental measurement results presented in this paper provide useful information for better understanding of cross-ventilation in highly-dense urban configurations which is the case for many modern cities. Moreover, the results can be used for validation of numerical models developed for urban studies in dense urban areas. An important finding of this study is the transient nature of the cross-ventilation flow in highly-dense urban configurations, which is generally omitted in steady state models in literature.

Flow visualizations reveals a significant difference in the air flow distribution and cross-ventilation performance between the moderate $\left(\lambda_{P}=0.25\right)$ and higher planar area ratios $\left(\lambda_{P}=0.4\right.$ and $\lambda_{P}=$ $0.6)$. In the case of highly-dense urban configurations, the fresh air periodically enters the building through both windward and leeward openings with different frequencies. A strong lee vortex can be observed for highly-dense building configurations, which creates a leeward jet around the leeward opening penetrating through the cross-ventilated building. The characteristics of the leeward jet in terms of oscillation frequency, sweeping angle, penetration length, and vortex structure are also discussed over both vertical and horizontal planes. It is shown that the frequency of the windward jet, generated due to the street canyon flow impingement on the building walls, is different with the frequency of the leeward jet generated by the lee vortex. Furthermore, a highly transient flapping jet and a Kelvin-Helmholtz instability can be clearly observed for both windward and leeward jet against different wind angles.

Measurement of the wind surface pressure over the building surfaces shows the effect of urban configuration (e.g., planar area ratio) and wind angle on the variation of the local wind surface pressure coefficient over internal and external building surfaces. Different trends are reported for different planar area ratios. For example, a significant reduction of the total surface pressure difference coefficient can be found when the planar area ratio increases from 0.25 to 0.4 and 0.6. 
The crossing airflow rate is also shown to significantly be reduced when the planar area ratio raises from moderately-dense to highly-dense building configurations.

Furthermore, presence of the leeward jet is found to negatively affect the accuracy of the tracer gas method for the highly-dense urban arrangement. In other words, application of the tracer gas method was found to be challenging for high planar area ratios of 0.4 and 0.6 due to the violation of the requirement of a fully-mixing condition for the airflow and tracer gas. Furthermore, a very limited number of pressure taps were used for the measurement of wind surface pressure over the building walls in order to minimize the blockage effect of the pressure tubes on the internal flow field. Nevertheless, to understand the detailed distribution of the wind pressure more pressure taps are required. Moreover, in this study, one layer of surrounding buildings were considered in order to minimize the blockage ratio of the wind tunnel and due to the limitations caused by the building dimensions over the turntable. More buildings layers is required to obtain general behavior of the cross-ventilation in real urban conditions. Future works focus on numerical aspects of cross-ventilation simulation in highly-dense urban configurations and experimental aspects by utilization of the particle image velocimetry (PIV) technique.

\section{Acknowledgement}

Faculty of engineering of the University of Nottingham is acknowledged for the financial support. The authors would like to express their gratitude for the financial support provided to the second author through Grants-in-Aid for Scientific Research in Japan (No. 16H04467). The authors also thank Mr. Y. Nishigata, an undergraduate student of Niigata Institute of Technology, for his valuable support in the experiment. Also, the authors would like to express their gratitude to Professor Akashi Mochida, Tohoku University, Japan and acknowledge his invaluable support and constructive suggestions during the planning and development of this research work.

\section{References}

Abdullah, A.H., Wang, F., 2012. Design and low energy ventilation solutions for atria in the tropics. Sustain. Cities Soc. 2, 8-28. https://doi.org/https://doi.org/10.1016/j.scs.2011.09.002

Aboelata, A., Sodoudi, S., 2019. Evaluating urban vegetation scenarios to mitigate urban heat island and reduce buildings' energy in dense built-up areas in Cairo. Build. Environ. 106407.

Aflaki, A., Mahyuddin, N., Mahmoud, Z.A.-C., Baharum, M.R., 2015. A review on natural ventilation applications through building façade components and ventilation openings in tropical climates. Energy Build. 101, 153-162.

Akabayashi, S., Mochida, A., Tominaga, Y., Yoshida, M., Sakaguchi, J., 1996. Performance of new wind tunnel of Niigata Institute of Technology. Wind Eng. JAWE 1996, 95-106.

Aydin, Y.C., Mirzaei, P.A., 2016. Wind-driven ventilation improvement with plan typology alteration: A CFD case study of traditional Turkish architecture, in: Building Simulation. Springer, pp. 1-16.

Becker, S., Lienhart, H., Durst, F., 2002. Flow around three-dimensional obstacles in boundary layers. J. Wind Eng. Ind. Aerodyn. 90, 265-279. https://doi.org/https://doi.org/10.1016/S0167-6105(01)00209-4

Cheng, H., Castro, I.P., 2002. Near Wall Flow over Urban-like Roughness. Boundary-Layer 
Meteorol. 104, 229-259. https://doi.org/10.1023/A:1016060103448

Coceal, O., Thomas, T.G., Castro, I.P., Belcher, S.E., 2006. Mean Flow and Turbulence

Statistics Over Groups of Urban-like Cubical Obstacles. Boundary-Layer Meteorol. 121, 491-519. https://doi.org/10.1007/s10546-006-9076-2

Gautam, K.R., Rong, L., Zhang, G., Abkar, M., 2019. Comparison of analysis methods for winddriven cross ventilation through large openings. Build. Environ. 154, 375-388.

Gough, H., Sato, T., Halios, C., Grimmond, C.S.B., Luo, Z., Barlow, J.F., Robertson, A., Hoxey, R., Quinn, A., 2018. Effects of variability of local winds on cross ventilation for a simplified building within a full-scale asymmetric array: Overview of the Silsoe field campaign. J.

Wind Eng. Ind. Aerodyn. 175, 408-418. https://doi.org/https://doi.org/10.1016/j.jweia.2018.02.010

Gough, H.L., Luo, Z., Halios, C.H., King, M.-F., Noakes, C.J., Grimmond, C.S.B., Barlow, J.F., Hoxey, R., Quinn, A.D., 2018. Field measurement of natural ventilation rate in an idealised full-scale building located in a staggered urban array: Comparison between tracer gas and pressure-based methods. Build. Environ. 137, 246-256.

Gryning, S.-E., Batchvarova, E., 2009. Measuring meteorology in urban areas-some progress and many problems, in: Meteorological and Air Quality Models for Urban Areas. Springer, pp. 125-131.

Guo, W., Liu, X., Yuan, X., 2015. Study on Natural Ventilation Design Optimization Based on CFD Simulation for Green Buildings. Procedia Eng. 121, 573-581.

Hesaraki, A., Myhren, J.A., Holmberg, S., 2015. Influence of different ventilation levels on indoor air quality and energy savings: A case study of a single-family house. Sustain. Cities Soc. 19, 165-172. https://doi.org/https://doi.org/10.1016/j.scs.2015.08.004

Ikegaya, N., Hasegawa, S., Hagishima, A., 2019. Time-resolved particle image velocimetry for cross-ventilation flow of generic block sheltered by urban-like block arrays. Build. Environ. $147,132-145$.

Ishida, Y., Okaze, T., Mochida, A., 2018. Influence of urban configuration on the structure of kinetic energy transport and the energy dissipation rate. J. Wind Eng. Ind. Aerodyn. 183, 198-213.

King, M.-F., Gough, H.L., Halios, C., Barlow, J.F., Robertson, A., Hoxey, R., Noakes, C.J., 2017a. Investigating the influence of neighbouring structures on natural ventilation potential of a full-scale cubical building using time-dependent CFD. J. Wind Eng. Ind. Aerodyn. 169, 265-279.

King, M.-F., Khan, A., Delbosc, N., Gough, H.L., Halios, C., Barlow, J.F., Noakes, C.J., $2017 b$. Modelling urban airflow and natural ventilation using a GPU-based lattice-Boltzmann method. Build. Environ. 125, 273-284.

Kotani, H., Goto, T., Ohba, M., Kurabuchi, T., 2009. Review of cross-ventilation research papers-from the working group for natural ventilation and cross-ventilation of the Architectural Institute of Japan. Int. J. Vent. 8, 233-241.

Kubota, T., Miura, M., Tominaga, Y., Mochida, A., 2008. Wind tunnel tests on the relationship between building density and pedestrian-level wind velocity: Development of guidelines for realizing acceptable wind environment in residential neighborhoods. Build. Environ. 43, 1699-1708.

Li, D., Zheng, Y., Liu, C., Qi, H., Liu, X., 2016. Numerical analysis on thermal performance of naturally ventilated roofs with different influencing parameters. Sustain. Cities Soc. 22, 8693.

Lo, L.J., Novoselac, A., 2012. Cross ventilation with small openings: Measurements in a multizone test building. Build. Environ. 57, 377-386. https://doi.org/http://dx.doi.org/10.1016/j.buildenv.2012.06.009

Lu, M., Du, J., 2019. Dynamic evaluation of daylight availability in a highly-dense Chinese residential area with a cold climate. Energy Build. 193, 139-159. 
Luo, Z., Li, Y., Wei-Zhen, L., 2011. Effects of Urban Ventilation Patterns on the Carbon Monoxide Concentration in a High-Rise Mega City. Int. J. Vent. 10, 239-250. https://doi.org/10.1080/14733315.2011.11683952

Mfula, A.M., Kukadia, V., Griffiths, R.F., Hall, D.J., 2005. Wind tunnel modeling of urban building exposure to outdoor pollution. Atmos. Environ. 39, 2737-2745. https://doi.org/10.1016/j.atmosenv.2004.07.040

Mirzaei, P.A., Haghighat, F., 2011. Pollution removal effectiveness of the pedestrian ventilation system. J. Wind Eng. Ind. Aerodyn. 99, 46-58.

Mirzaei, P.A., Olsthoorn, D., Torjan, M., Haghighat, F., 2015. Urban neighborhood characteristics influence on a building indoor environment. Sustain. Cities Soc. 19, 403413. https://doi.org/https://doi.org/10.1016/j.scs.2015.07.008

Mochida, A., Yoshino, H., Miyauchi, S., Mitamura, T., 2006. Total analysis of cooling effects of cross-ventilation affected by microclimate around a building. Sol. Energy 80, 371-382.

Mochida, A., Yoshino, H., Takeda, T., Kakegawa, T., Miyauchi, S., 2005. Methods for controlling airflow in and around a building under cross-ventilation to improve indoor thermal comfort. J. Wind Eng. Ind. Aerodyn. 93, 437-449. https://doi.org/http://dx.doi.org/10.1016/j.jweia.2005.02.003

Montazeri, H., Blocken, B., 2013. CFD simulation of wind-induced pressure coefficients on buildings with and without balconies: validation and sensitivity analysis. Build. Environ. 60, 137-149.

OECD, 2012. OECD environmental outlook to 2050: The consequences of inaction. OECD Publishing.

Ohba, M., Irie, K., Kurabuchi, T., 2001. Study on airflow characteristics inside and outside a cross-ventilation model, and ventilation flow rates using wind tunnel experiments. J. Wind Eng. Ind. Aerodyn. 89, 1513-1524. https://doi.org/https://doi.org/10.1016/S01676105(01)00130-1

Park, J.S., 2013. Long-term field measurement on effects of wind speed and directional fluctuation on wind-driven cross ventilation in a mock-up building. Build. Environ. 62, 1-8. https://doi.org/http://dx.doi.org/10.1016/j.buildenv.2012.12.013

Prakash, D., Ravikumar, P., 2015. Analysis of thermal comfort and indoor air flow characteristics for a residential building room under generalized window opening position at the adjacent walls. Int. J. Sustain. Built Environ. 4, 42-57. https://doi.org/http://dx.doi.org/10.1016/j.ijsbe.2015.02.003

Quan, Y., Tamura, Y., Matsui, M., Cao, S., Yoshida, A., Xu, S., 2007. Interference effect of a surrounding building group on wind loads on flat roof of low-rise building: Part I, Distribution of local wind pressure coefficient. Wind Eng. JAWE 32, 211-212.

Ramponi, R., Blocken, B., de Coo, L.B., Janssen, W.D., 2015. CFD simulation of outdoor ventilation of generic urban configurations with different urban densities and equal and unequal street widths. Build. Environ. 92, 152-166. https://doi.org/10.1016/J.BUILDENV.2015.04.018

Shirzadi, M., Mirzaei, P.A., Naghashzadegan, M., Tominaga, Y., 2018a. Modelling enhancement of cross-ventilation in sheltered buildings using stochastic optimization. Int. J. Heat Mass Transf. 118. https://doi.org/10.1016/j.ijheatmasstransfer.2017.10.107

Shirzadi, M., Naghashzadegan, M., A. Mirzaei, P., 2018b. Improving the CFD modelling of cross-ventilation in highly-packed urban areas. Sustain. Cities Soc. 37. https://doi.org/10.1016/j.scs.2017.11.020

Shirzadi, M., Tominaga, Y., Mirzaei, P.A., 2019. Wind tunnel experiments on cross-ventilation flow of a generic sheltered building in urban areas. Build. Environ. 158, 60-72. https://doi.org/10.1016/J.BUILDENV.2019.04.057

Shuhaimi, S.S., Zaki, S.A., Ali, M.S.M., Huda, A.N., Yakub, F., 2017. Numerical estimation of natural ventilation of cubical urban arrays with different packing density, in: MATEC Web of 
Conferences. EDP Sciences, p. 1008.

Snyder, W.H., Castro, I.P., 2002. The critical Reynolds number for rough-wall boundary layers. J. Wind Eng. Ind. Aerodyn. 90, 41-54.

Tan, Z., Chung, S.C., Roberts, A.C., Lau, K.K.-L., 2019. Design for climate resilience: influence of environmental conditions on thermal sensation in subtropical high-density cities. Archit. Sci. Rev. 62, 3-13. https://doi.org/10.1080/00038628.2018.1495612

Tominaga, Y., Akabayashi, S., Kitahara, T., Arinami, Y., 2015. Air flow around isolated gableroof buildings with different roof pitches: Wind tunnel experiments and CFD simulations. Build. Environ. 84, 204-213.

Tominaga, Y., Blocken, B., 2015. Wind tunnel experiments on cross-ventilation flow of a generic building with contaminant dispersion in unsheltered and sheltered conditions. Build. Environ. 92, 452-461.

Tominaga, Y., Mochida, A., Yoshie, R., Kataoka, H., Nozu, T., Yoshikawa, M., Shirasawa, T., 2008. AlJ guidelines for practical applications of CFD to pedestrian wind environment around buildings. J. Wind Eng. Ind. Aerodyn. 96, 1749-1761.

Tominaga, Y., Stathopoulos, T., 2011. CFD modeling of pollution dispersion in a street canyon: Comparison between LES and RANS. J. Wind Eng. Ind. Aerodyn. 99, 340-348.

Tong, Z., Chen, Y., Malkawi, A., 2016. Defining the Influence Region in neighborhood-scale CFD simulations for natural ventilation design. Appl. Energy 182, 625-633.

Uehara, K., Wakamatsu, S., Ooka, R., 2003. Studies on critical Reynolds number indices for wind-tunnel experiments on flow within urban areas. Boundary-Layer Meteorol. 107, 353370.

Wang, W., Ng, E., Yuan, C., Raasch, S., 2017. Large-eddy simulations of ventilation for thermal comfort - A parametric study of generic urban configurations with perpendicular approaching winds. Urban Clim. 20, 202-227. https://doi.org/https://doi.org/10.1016/j.uclim.2017.04.007

Wu, S.-Y., Shen, Z.-G., Xiao, L., Li, D.-L., 2015. Experimental study on combined convective heat loss of a fully open cylindrical cavity under wind conditions. Int. J. Heat Mass Transf. 83, 509-521. https://doi.org/http://doi.org/10.1016/j.ijheatmasstransfer.2014.12.029

Yang, L., Li, T., Wong, S.C., Shu, C.-W., Zhang, M., 2019. Modeling and simulation of urban air pollution from the dispersion of vehicle exhaust: A continuum modeling approach. Int. J. Sustain. Transp. 13, 722-740. https://doi.org/10.1080/15568318.2018.1510563

Yang, L., Li, Y., 2011. Thermal conditions and ventilation in an ideal city model of Hong Kong. Energy Build. 43, 1139-1148. https://doi.org/https://doi.org/10.1016/j.enbuild.2010.06.005

Yoshie, R., Mochida, A., Tominaga, Y., Kataoka, H., Harimoto, K., Nozu, T., Shirasawa, T., 2007. Cooperative project for CFD prediction of pedestrian wind environment in the Architectural Institute of Japan. J. Wind Eng. Ind. Aerodyn. 95, 1551-1578.

Yuan, C., Ng, E., Norford, L.K., 2014. Improving air quality in high-density cities by understanding the relationship between air pollutant dispersion and urban morphologies. Build. Environ. 71, 245-258. 